\title{
belarus-
}

analysen

\section{PRÄSIDENTSCHAFTSWAHLEN COVID-19 IN BELARUS}

\section{ANALYSE}

Zum ersten Mal seit 1994 gibt es keine Garantie für Lukaschenkas Wiederwahl

Pavel Bykouski (Journalist, Medienexperte und politischer Beobachter, Minsk)

STATISTIK

Präsidentschaftswahlen

ANALYSE

Belarus vor den Wahlen: Einige soziologische Aspekte

Andrei Vardomatski (Belarusian Analytical Workroom, Warschau)

\section{ANALYSE}

Covid-19: Zur Frage der "statistischen Anomalie« in Belarus

Piotr Rudkouski (Belarussisches Institut für Strategische Studien - BISS, Minsk)

STATISTIK

Covid-19 in Belarus im Vergleich

CHRONIK

Covid-19-Chronik, 13. April - 14. Juni 2020

CHRONIK

14. April - 14. Juni 2020

\section{Deutsches}

Polen-Institut

DEUTSCHES

POLEN

INSTITUT
Leibniz-Institut für Ost- und Südosteuropaforschung
Zentrum für Osteuropa- und internationale Studien (ZOiS) gGmbH 


\title{
Zum ersten Mal seit 1994 gibt es keine Garantie für Lukaschenkas Wiederwahl
}

\author{
Pavel Bykouski (Journalist, Medienexperte und politischer Beobachter, Minsk)
}

DOI: 10.31205/BA.050.01

\section{Zusammenfassung}

Zum ersten Mal in den 26 Jahren der Herrschaft von Aljaksandr Lukaschenka in Belarus stehen Präsidentschaftswahlen an, die vom Präsidenten und von der Gesellschaft als Wahlen betrachtet werden, bei denen es einen Wettbewerb gibt und das Ergebnis nicht im Voraus feststeht. Es gibt bei den Wahlen eine personelle Alternative zu Lukaschenka, und der amtierende Präsident beschuldigt seine Konkurrenten, sie würden Verbindungen zu Russland unterhalten, auch wenn er selbst mit der Parole einer Integration von Belarus und Russland aufgetreten ist. Dieser Beitrag bietet eine kurze Analyse der wichtigsten Tendenzen bei diesen Wahlen.

\section{Der Hintergrund}

Das Repräsentantenhaus der Nationalversammlung von Belarus hat am 8. Mai 2020 die Präsidentschaftswahlen auf den 9. August angesetzt. 55 Anwärter haben Anträge auf die Registrierung von Initiativgruppen eingereicht. Die Zentrale Wahlkommission hat 15 dieser Gruppen registriert, und die haben seit dem 21. Mai begonnen, die ersten der 100.000 für die Registrierung eines Kandidaten erforderlichen Unterschriften zu sammeln.

Vertreter der traditionellen Opposition hatten wegen der Covid-19-Pandemie keine Vorwahlen zur Bestimmung eines gemeinsamen Kandidaten abhalten können und haben drei Initiativgruppen registrieren lassen. Sie nutzen den Wahlkampf, um ihre Ansichten in der Bevölkerung zu verbreiten und sammeln keine Unterschriften.

Bis zum 15. Juni 2020 hatten der amtierende Aljaksandr Lukaschenka und auch der ehemalige Vorstandsvorsitzende der Belgazprombank, Viktar Babaryka, die ehemalige oppositionelle Abgeordnete des Repräsentantenhauses Hanna Kanapazkaja und der ehemalige Direktor des Hightech-Parks, Walery Zapkala, erklärt, dass sie die Hürde dieser 100.000 Unterschriften überwunden haben. Darüber hinaus werden vom Anführer der Kampagne "Sprich die Wahrheit!«, Andrej Dsmitryjeu, der Ehefrau des populären Videobloggers Sjarhej Zichanouski, Swjatlana Zichanouskaja (ihr Gatte hat wegen seiner Haft keine Initiativgruppe registrieren lassen können) und dem Chef der Partei »Belaruskaja Sazyjal-demakratytschnaja Hramada» (»Belarussische Sozialdemokratische Gesellschaft«), Sjarhej Tscheratschen, Unterschriften gesammelt.

Die Entscheidung über die Registrierung der Kandidaten wird nach der Überprüfung der Unterschriften in der Zeit vom 5. bis zum 14. Juli erfolgen, wonach der eigentliche Wahlkampf beginnt.

\section{Sechs Tendenzen in diesem Wahlkampf}

1. Fehlerhafte Einschätzung im Vorfeld. Freie und faire Präsidentschaftswahlen mit Wettbewerbscharakter hat 2020 niemand in Belarus erwartet. Es wurde vielmehr angenommen, dass Aljaklsandr Lukaschenka, dem autoritären Präsidenten in Belarus, auf jeden Fall eine Verlängerung seiner Amtszeit beschieden sei. Jetzt allerdings wird es zu einem Stresstest kommen. Der Wahlprozess erfolgt vor dem Hintergrund der weltweiten Wirtschaftskrise, der Covid-19-Pandemie, des fortgesetzten Streits mit Russland und der Schwächung der belarussischen Opposition. All diese Faktoren wären, jeder für sich genommen, für Lukaschenka zu bewältigen oder sogar wünschenswert, doch zusammengenommen sorgen sie für große Ungewissheit.

2. Die Covid-19-Pandemie ist zu einem unerwarteten Faktor geworden: Die Unterschriftensammler müssen mit Schutzkleidung arbeiten, Massenveranstaltungen werden von der Gesellschaft nicht gutgeheißen, von Tür zu Tür zu laufen, ist wegen der Angst vor Ansteckung erschwert, und Anhänger eines Wahlboykotts haben die Unterschriftensammler als Verbreiter der Epidemie bezeichnet. Lukaschenka ist als "Covid-19-Dissident" in Erscheinung getreten, indem er sich der öffentlichen Meinung nicht nur weltweit, sondern auch in Belarus entgegengestellt hat (einer Umfrage des Marktforschungsinstituts SATIO vom April zufolge traten $74 \%$ der Belarussen für ein Verbot von Massenveranstaltungen ein - gleichwohl wurde am 9. Mai die Siegesparade abgehalten). Die Empörung über das Vorgehen der Regierung brachte einen Teil der Bevölkerung dazu, sich als freiwillige Unterstützer bei alternativen Kandidaten zu melden.

3. Potenzielle Schwergewichte unter den Kandidaten verstärken die Ungewissheit, wie die Wahlen ausge- 
hen werden. Der ehemalige Banker Viktar Babaryka und der ehemalige Bürokrat Walery Zapkala sind unerwartet zu Hoffnungsträgern der gemäßigten Reformanhänger geworden, die der endlosen Herrschaft Lukaschenkas und der Misserfolge der traditionellen Opposition müde sind. Sie haben Gewicht, eine Erfolgsgeschichte, und sie sind definitiv keine Radikalen. Sie können den Traum von einem gewissen dritten Weg erfüllen, den Traum von einem sanften Machtwechsel ohne Revolution und Erschütterungen, von einer Abkehr von der Archaik des autoritären Regimes hin zu westlichem Liberalismus und Demokratie, von neuen Organisationsmethoden des Staates und der Gesellschaft, die sich auf Partnerschaft, Zusammenarbeit und horizontale Kooperation stützen, und dabei nicht gegen Russland gerichtet sind. Das erzeugt zusätzliche Risiken für das Regime, selbst wenn die Kontrolle über die Organisation der Wahlen und der Stimmauszählung beibehalten wird.

4. Die Unterstützung für die Regierung ist zurückgegangen, und zwar allem Anschein so sehr, dass ein Wahlsieg Lukaschenkas im ersten Durchgang nicht garantiert erscheint. Seit 2016 sind in Belarus keine wahlbezogenen Umfragen veröffentlicht worden. In dieser Situation stellen OnlineAbstimmungen einen gewissen Indikator für die Stimmungslage in der Gesellschaft dar (sie sind allerdings nicht repräsentativ). Diesen Abstimmungen zufolge würde Lukaschenka lediglich 3 - 5 Prozent der Stimmen erhalten, während Babaryka auf 50 - 55 Prozent hoffen könnte. Für gewöhnlich werden die Konkurrenten im Wahlkampf vom amtierenden Präsidenten ausdrücklich "nicht bemerkt«. Nun jedoch ist es so, dass Lukaschenka auf sie losgeht und sie mit Kritik überschüttet (»die sind aus ihren Löchern gekrochen gekommen und versprechen Geld und das Blaue vom Himmel«).

5. Aufschwung gesellschaftlicher Aktivität bei einer gleichzeitigen Marginalisierung der politischen Opposition. All die 26 Jahre seiner Herrschaft hat Lukaschenka die Opposition unterdrückt. Das hat dazu geführt, dass die Opposition als politische Kraft weder zu einem Filter geworden ist, der jene potenzielle Kandidaten auswählen hilft, die die Interessen der Verfechter von Veränderungen vertreten, noch dass sie selbst einen solchen Kandidaten hervorbringen konnte. Anstelle von prägnanten Oppositionspolitikern ist nun der Videoblogger Sjarhej Zichanouski zu einem der wichtigsten Akteure dieser Wahlen geworden. Zichanouski ist erst im Frühjahr 2019 in die Politik gegangen. Sein YouTube-Kanal »Ein Land zum
Leben « ist ein Sammelplatz für den Unmut geworden, der in der Bevölkerung über die Regierung herrscht. Er hat den Wahlkampf in eine ProtestPerformance verwandelt und massenweise Menschen versammelt: Die Leute standen Dutzende Meter Schlange, um "gegen Lukaschenka zu unterschreiben«. Dadurch hat Zichanouski Menschen zu Protest anregen können, die früher apolitisch waren, und sogar solche, die bislang dem Regime gegenüber loyal waren. Nach einem Zwischenfall, den viele als Provokation eingeschätzt haben, wurde er in Untersuchungshaft genommen. Belarussische Menschenrechtler haben ihn als politischen Gefangenen bezeichnet. In russischen Medien figuriert er unter anderem als »belarussischer Nawalnyj «.

6. Die "Hand Moskaus« zur Brandmarkung der Opponenten Lukaschenkas. Die staatliche Propaganda stellt Zichanouski als russischen Handlanger dar, der versuche, in Belarus Massenunruhen zu organisieren. Die »Hand Moskau« wird auch hinter Babaryka und hinter Zapkala gesehen. Die Meinungen der Experten über das Geschehen gehen in dieser Hinsicht auseinander. Der Politologe Dsmitryj Balkunez vom Moskauer Staatlichen Institut für Internationale Beziehungen (MGIMO) hat bereits im April behauptet, dass "Lukaschenka ohne Unterstützung durch den Kreml in die Präsidentschaftswahlen geht «. Dem gegenüber führte beispielsweise der stellvertretende Chefredakteur von Carnegie. $r u$, Maxim Samorukow, im Juni aus, dass »Lukaschenka für den Kreml nützlich ist und es keinen ernstzunehmenden Plan gibt, Lukaschenka abzusetzen«. Der zur "Gazprom-Media«-Holding gehörende Radiosender "Echo Moskwy" formulierte seine Botschaft so: »Belgazprombank und der Präsidentschaftskandidat Viktar Babaryka vertreten nicht die Interessen Russlands und hatten niemals politische Kontakte zur Leitung von Gazprom«. Es wird darauf verwiesen, dass Viktar Babaryka dies "Echo Moskwy« selbst in einem Interview gesagt habe.

Ein wichtiges Detail: Für gewöhnlich tritt bei den Wahlen die proeuropäische Opposition als Lukaschenkas Gegenspieler in Erscheinung, als Kraft, die für die Souveränität des Landes eintritt und gegen eine vertiefte Integration von Belarus und Russland kämpft. Jetzt ist die Opposition von der Wahl ausgeschlossen, und die wichtigsten Konkurrenten Lukaschenkas (Babaryka und Zapkala) haben beachtenswerte Verbindungen nach Russland. Dadurch spielen nun bei den Wahlen 2020 Lukaschenka und die ehemalige Parlamentsabgeordnete Hanna Kanapazkaja die Rolle der wichtigsten Verteidiger der Souveränität. 


\section{Reaktion der Regierung und Prognose zur Registrierung der Kandidaten sowie dem Ausgang der Wahlen}

Die Logik der Ereignisse zwingt das Regime zu verstärkten Repressionen. Der Präsident erklärt: »Wir haben das Land ererbt. [...] Und wir werden dieses Land niemandem aushändigen!« Lukaschenkas Konkurrenten bei den Wahlen werden als Handlanger des Willens ausländischer Zentren hingestellt, die das Ziel verfolgen, Belarus seiner Unabhängigkeit zu berauben.

Seit Anfang Juni fanden die Sitzungen von Lukaschenka mit den Silowiki wöchentlich statt. Am Vorabend des Wahlganges wurde der stellvertretende Vorsitzende des KGB, Ihar Sjarhejenka, an die Spitze eines der wichtigsten Machtzentren in Belarus gesetzt, der Präsidialadministration. Und mitten in der heißen Phase der Vorwahlzeit wurde der Chef des "Staatlichen Militärisch-Industriellen Komitees« (DWPK/ Gosvoenprom), Raman Haloutschanka, der den Geheimdiensten entstammt, Regierungschef. Pjotr Petrouski, Experte des Analysezentrums der präsidentenfreundlichen gesellschaftlichen Organisation "Belaja Rus» ("Weiße Rus»), erklärte in einem Interview mit der "Deutschen Welle" diesen Schritt damit, dass sich die Führung des Landes für die Zeit der Präsidentschaftswahlen absichert: "Denen da oben ist klar, dass Babaryka versuchen wird, so mit den Eliten umzugehen, dass es dort zu einer Spaltung kommt."

Der Umstand, dass es Babaryka im Laufe weniger Tage gelang, in den sozialen Netzwerken über 10.000 Anträge auf Teilnahme in der Initiativgruppe zu sammeln (und 335.000 Unterschriften in nicht einmal einem Monat), wie auch die massenhaften begeisterten Posts über den ehemaligen Bankier, die von Unternehmern und Angehörigen der künstlerischen Intelligenz erfolgten, haben ihn zum wichtigsten Herausforderer von Lukaschenka gemacht. Der amtierende Präsident hat seinen Konkurrenten bereits beschuldigt, in der von Babaryka geleiten »Belgazprombank« eine kriminelle Vereinigung geschaffen zu haben. Polizei und Justiz haben dort eine Durchsuchung vorgenommen. Die Nationalbank von Belarus hat eine provisorische Verwaltung eingesetzt. "Gazprom», letztendlich fast zu Hälfte der Eigentümer der Bank, hat dies und die Festnahme der Leitung der "Belgazprombank« als rechtswidrig bezeichnet. 15 Mitglieder der Initiativgruppe für Babaryka sind festgenommen worden. Bei einigen seiner Freunde und bei einigen mit der "Belgazprombank« verbundenen Firmen gab es Hausdurchsuchungen. Schon vor der Festnahme Babarykas am 18. Juni war die Möglichkeit, dass der ehemalige Bankier verhaftet werden könnte, ernsthaft diskutiert worden, auch wenn Lukaschenka behauptet, dass er ihn nicht zu einem politischen Gefangenen machen wollte.
Die Registrierung der Präsidentschaftskandidaten ist in Belarus keine rein formale Angelegenheit, da die Unterschriftenprüfung durch die Wahlkommissionen oft als Filter dient, um missliebige Politiker auszuschließen. Bisher ist es in Belarus noch nie vorgekommen, dass einem potenziellen Präsidentschaftskandidaten, der in der Tat die 100.000 Unterschrift gesammelt hatte, die Registrierung verweigert wurde, doch besteht diese Praxis nach Angaben der Opposition und von Menschenrechtlern durchaus bei Parlamentswahlen.

Es ist bislang unklar, wie sich die Situation 2020 entwickeln wird. Lukaschenka erklärt über Babaryka: "[...] ich will, dass er es zu den Wahlen schafft«. Es erscheint wahrscheinlich, dass die Behörden Babaryka und Zapkala registrieren werden, damit die Wahl spannend bleibt, die Kandidaten Wähler anziehen - und sich dadurch gegenseitig die Stimmen wegnehmen.

Auch durch die Festnahme von Viktar Babaryka und dessen Sohn am 18. Juni wird die Ungewissheit nicht verringert. Die beiden werden verdächtigt, Wirtschaftsverbrechen begangen zu haben. Für den ehemaligen Bankier ist die notwendige Zahl an Unterschriften eingereicht worden, er ist nicht vorbestraft und wird es auch kaum am 5. Juli sein, wenn die Zentrale Wahlkommission mit der Registrierung der Kandidaten beginnt. Das heißt, die Tatsache der Verhaftung, eine möglicherweise erhobene Anklage und selbst der Beginn eines Gerichtsprozesses bieten keine Grundlage, um die Registrierung zu verweigern.

Falls Babaryka unter irgendeinem Vorwand die Registrierung verweigert werden sollte, Zapkala aber als Kandidat registriert wird, würde letzterer sofort gestärkt und der Kandidat eines Großteils der Anhänger von Veränderungen werden.

Es ist nicht ausgeschlossen, dass anstelle der beiden nur Kanapazkaja registriert wird, die weniger den Präsidenten kritisiert, sondern vielmehr Babaryka. Dann verlören die Wahlen ihre Spannung.

Eine andere Variante wäre, wenn weder Babaryka, Zapkala und Kanapazkaja registriert werden und der verstoßene Oppositionsführer von "Sprich die Wahrheit!«, Andrej Dsmitryjeu, auf dem Stimmzettel die Rolle des Sparringpartners von Lukaschenka übernimmt.

Babarykas Mitstreiter präsentierten am 19. Juni eine vorab aufgezeichnete Videobotschaft, in der Babaryka seine Anhänger dazu aufruft, ein Referendum über eine Rückkehr des Landes zur Verfassung von 1994 zu initiieren, mit der einigermaßen eine Gewaltenteilung und ein weniger zahnloses Parlament bestehen würde. Eine solche Initiative lässt sich wohl unmöglich in der Praxis umsetzen. Ein Referendum muss mit dem Justizministerium und der Generalstaatsanwaltschaft abgestimmt werden. Noch wichtiger aber ist: Die letztendliche Entscheidung über die Ansetzung einer Volksabstim- 
mung fällt eh der Präsident. Ein Verfahren, mit dem eine Weigerung des Präsidenten hinsichtlich der Ansetzung eines Referendums angefochten werden könnte, ist nicht vorgesehen.

Allerdings könnte diese Initiative schon heute die Gelegenheit bieten, die Anhänger Babarykas für eine Fortsetzung ihres politischen Engagements zu mobilisieren.

Das bedeutet, es gibt zwei Grundlagen, dass Babaryka weiterhin im politischen Spiel bleibt, nämlich als potenzieller Präsidentschaftskandidat und als Initiator eines Referendums. Selbst wenn die Zentrale Wahlkommission die Initiativgruppe nicht registrieren sollte, könnte das gleiche Koordinationsteam rechtmäßig eine neue Gruppe bilden, seine Tätigkeit im Medienbereich fortsetzen und Freiwillige rekrutieren.

Es ist möglich, dass die Hoffnung von heute zur Enttäuschung von morgen wird. Babaryka und Zapkala sagen, dass sie nicht vorhaben, im Falle von Wahlfälschungen zu Straßenprotesten aufzurufen. Sie würden allerdings hinzukommen, wenn sich die Menschen schon versammelt haben. Falls sie am Ende Lukaschenka zum Sieg gratulieren sollten, wird das bei ihren Anhängern eine Welle der Enttäuschung auslösen, da ein Groß- teil ihrer Wählerschaft früher nicht an Straßenprotesten teilgenommen hat und kaum in der Lage sein dürfte, sich selbst zu organisieren.

Was die traditionelle Opposition betrifft, so nimmt die nicht an den Wahlen teil, verfügt also über keine ernstzunehmende Begründung, sich an der Organisation von Protesten beteiligen.

Bis Anfang Mai hatte es in Belarus praktisch keine öffentliche Politik gegeben. Jetzt gibt es sie, zumindest bis zum 9. August. Der Gesellschaft wurde deutlich gemacht, dass die "Kandidaten der Hoffnung« - Babaryka und Zapkala - kein Projekt der Präsidialadministration sind (einige haben sie dessen verdächtigt). Bislang ist unklar, wie sie dem Schlag gegen sie bei den Wahlen standhalten werden, und ob sie nach deren Abschluss sich weiter politisch betätigen werden.

Somit ist diese Wahl eine der wenigen in den vergangenen zwei Jahrzehnten, bei der niemand dafür seine Hand ins Feuer legt, dass Lukaschenka nicht für eine weitere Amtszeit wiedergewählt wird - das Gleiche gilt aber auch für seine mögliche Wiederwahl.

Übersetzung aus dem Russischen: Hartmut Schröder

\section{Über den Autor}

Pavel Bykouski ist Journalist, politischer Beobachter und Medienexperte. Er ist als Korrespondent der Deutschen Welle in Belarus akkreditiert. Zuvor (1995-2015) leitete er die Politiksparte und war Redaktionsmitglied der Wochenzeitung »Belorusy i rynok».

\section{Bibliografie}

- Dryndova, Olga: Belarusian spring? What we know about Belarusian society (Part 1), New Eastern Europe, June 24, 2020; https://neweasterneurope.eu/2020/06/24/belarusian-spring-what-we-know-about-belarusian-society/

- Dryndova, Olga: Belarusian spring? Politicisation of the wider society (Part 2), New Eastern Europe, July 8, 2020; https://neweasterneurope.eu/2020/07/08/belarusian-spring-politicisation-of-the-wider-society/

- Shkliarov, Vitali: Belarus. Who will win?, New Eastern Europe, July 2, 2020; https://neweasterneurope. eu/2020/06/24/belarusian-spring-what-we-know-about-belarusian-society/

- Shraibman, Artyom: Wen soll der Westen in Belarus unterstützen?, Zentrum Liberale Moderne, 29. Juni 2020; https://libmod.de/shraibman-wen-soll-der-westen-in-belarus-unterstuetzen/ 


\section{Präsidentschaftswahlen}

Grafik 1: Google-Suchanfragen in Belarus über potentielle Präsidentschaftskandidat_innen*

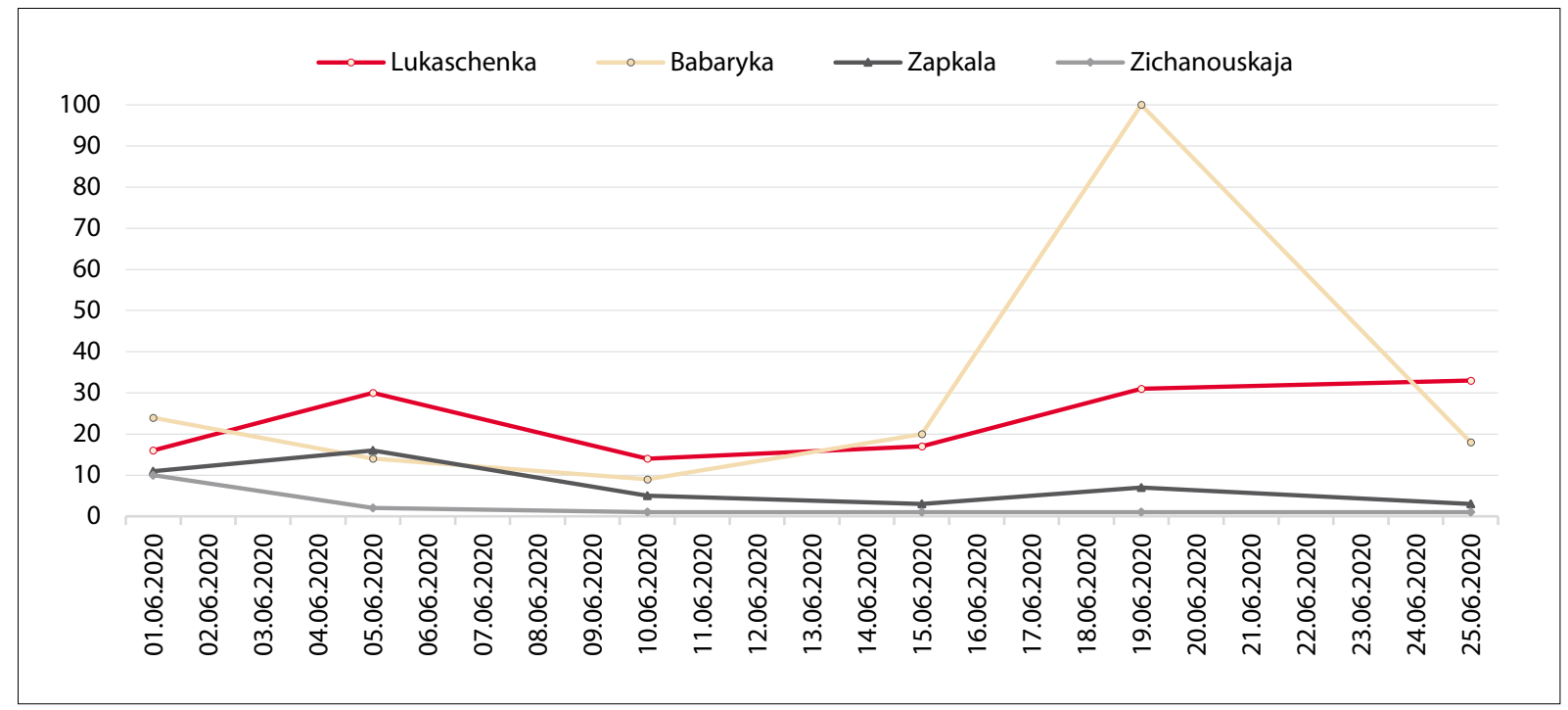

\begin{tabular}{|l|c|c|c|c|c|c|}
\hline & $\mathbf{0 1 . 0 6 . 2 0 2 0}$ & $\mathbf{0 5 . 0 6 . 2 0 2 0}$ & $\mathbf{1 0 . 0 6 . 2 0 2 0}$ & $\mathbf{1 5 . 0 6 . 2 0 2 0}$ & $\mathbf{1 9 . 0 6 . 2 0 2 0}$ & $\mathbf{2 5 . 0 6 . 2 0 2 0}$ \\
\hline Lukaschenka & 16 & 30 & 14 & 17 & 31 & 33 \\
\hline Babaryka & 24 & 14 & 9 & 20 & 100 & 18 \\
\hline Zapkala & 11 & 16 & 5 & 3 & 7 & 3 \\
\hline Zichanouskaja & 10 & 2 & 1 & 1 & 1 & 1 \\
\hline
\end{tabular}

* 1 bis 100 Punkte; Anmerkung: Die Zahlen stammen von Google Trends. Google Trends normalisiert Suchdaten, um Vergleiche zwischen Begriffen zu erleichtern. Die Ergebnisse erscheinen dann in einer Skala von 0 bis 100, die sich nach der Nachfrage nach einem Thema im Vergleich zu allen Suchanfragen für alle Themen richtet. (siehe https://support.google.com/trends/answer/4365533?hl=de\&ref_topic=6248052)

Quelle: Babaryka abahnau Lukaschenku u poschukawych sapytach Google, https://www.svaboda.org/a/30673958.html

Tabelle 1: Registrierung der Unterschriften für potentielle Präsidentschaftskandidat_innen durch die Zentrale Wahlkommission* (Stand: 8. Juli 2020)

\begin{tabular}{|c|c|c|c|c|c|}
\hline & $\begin{array}{l}\text { Eingereicht (laut } \\
\text { Aussagen der Ini- } \\
\text { tiativgruppen) }\end{array}$ & $\begin{array}{l}\text { Eingereicht (laut } \\
\text { Angaben der } \\
\text { Zentralen Wahl- } \\
\text { kommission) }\end{array}$ & $\begin{array}{c}\text { Davon } \\
\text { anerkannt }\end{array}$ & $\begin{array}{l}\text { Differenz zwischen den } \\
\text { eingereichten (laut ur- } \\
\text { sprünglichen Angaben } \\
\text { der Initiativgruppen) } \\
\text { und den anerkannten } \\
\text { Unterschriften }\end{array}$ & $\begin{array}{l}\text { Mehr registriert als ein- } \\
\text { gereicht (laut ursprüng- } \\
\text { lichen Angaben der } \\
\text { Initiativgruppen) }\end{array}$ \\
\hline $\begin{array}{l}\text { Aljaksandr } \\
\text { Lukaschenka }\end{array}$ & über 2.000 .000 & 1.958 .800 & 1.939 .572 & über 60.400 & \\
\hline Wiktar Babaryka & 365.000 & 367.179 & 165.744 & 199.256 & \\
\hline Walery Zapkala** & 200.000 & 158.682 & 75.249 & 124.751 & \\
\hline $\begin{array}{l}\text { Sjarhej } \\
\text { Tscheratschan }\end{array}$ & 106.000 & 149.750 & 143.109 & & 37.109 \\
\hline Hanna Kanapazkaja & 110.000 & 151.631 & 146.588 & & 36.588 \\
\hline Andrej Dsmitryjeu & 107.000 & 110.754 & 106.841 & 159 & \\
\hline $\begin{array}{l}\text { Swjatlana } \\
\text { Zichanouskaja }\end{array}$ & über 100.000 & 109.479 & 104.757 & keine Angaben & \\
\hline
\end{tabular}

* es werden mindestens 100.000 Unterschriften für eine Registrierung benötigt

** wird nicht als Präsidentschaftskandidat registriert

Quelle: Zusammengestellt auf Grundlage von Materialien des Nachrichtenportals tut.by 


\title{
Belarus vor den Wahlen: Einige soziologische Aspekte
}

\author{
Andrei Vardomatski (Belarusian Analytical Workroom, Warschau)
}

DOI: $10.31205 /$ BA.050.02

\section{Zusammenfassung}

Niemand hatte angenommen, dass die Präsidentschaftswahlen 2020 in Belarus sich als derart dramatisch herausstellen würden, wie es derzeit zu beobachten ist. Noch vor einem halben Jahr schien es, als würden sie lediglich eine Wiederholung der öden Wahlen von 2015. Die vielzähligen Stände der Initiativgruppen der alternativen Kandidaten, die mehrere Hundert Meter langen Schlangen von Leuten, die jedem Kandidaten, nur nicht Aljaksandr Lukaschenka ihre Unterschrift geben wollen, und das Erscheinen von ganz neuen potenziellen Kandidaten haben diese Wahlen überraschend und unberechenbar gemacht. Es gibt zwei Gründe, weswegen sie mit früheren Wahlen nicht vergleichbar sind: das Coronavirus und die gegenwärtige wirtschaftliche Lage von Belarus. In ihrem Zusammenspiel haben diese beiden Faktoren einen kumulativen Effekt. Die Lage der Wirtschaft ist im Vorfeld der Wahlen eine Art Schwarzpulver und das Coronavirus die Zündschnur dazu. Der Beitrag untermauert diese These mit einigen soziologischen Daten.

Die globale Covid-19-Pandemie, die Belarus wie auch die ganze Welt erfasst hat, förderte zwei wichtige Merkmale des belarussischen Staatsapparats und seiner Funktionsweise zu Tage. Das erste besteht in einer mangelnden Effizienz bei der Bewältigung von Krisensituationen; zweitens wird die Bevölkerung nicht ehrlich über die tatsächliche Lage im Land informiert. Das belegen einige empirische soziologische Daten.

Die größte internationale komparative soziologische Studie zum Thema Covid-19 ist der »International COVID19 Survey«, der in 58 Ländern durchgeführt wurde. Die Studie wurde durch Wissenschaftler von 12 der weltweit führenden Universitäten (u. a. Oxford, Harvard und Cambridge) erstellt. Die Befragung erfolgte online. Der Belarusian Analytical Workroom ist der offizielle Repräsentant dieser Studie auf dem Gebiet der Republik Belarus. Vom 20. März bis zum 6. April 2020 wurden weltweit über 100.000 Personen befragt, davon 3.300 in Belarus.

Das Besondere der Covid-19-Pandemie besteht in ihrer außerordentlichen Dynamik und Wechselhaftigkeit in jeder ihrer Phase. Die Zahlen in den Grafiken zeigen, dass das Land zu dem Zeitpunkt, als die Pandemie gerade Belarus erreicht hatte, sich jenseits der weltweiten Tendenzen befand. Gegenwärtig (Stand: 17. Juni) ist die Zahl der Infizierten in Belarus mit 6.573,81 Fällen pro einer Million Einwohner die höchste in ganz Europa und die nach Chile, Peru und den USA die vierthöchste in der Welt.

\section{1.}

In der Grafik 1 werden die Defizite in der Reaktion der Regierung auf die Pandemie dargestellt, wie sie in der Bevölkerung wahrgenommen werden. Die Einschätzung des Vorgehens der Regierung in Bezug auf den Ausbruch der

Grafik 1: Anteil der Befragten, die die Reaktion ihrer Regierung als unzureichend wahrnehmen (20.03.06.04.2020; in \%)

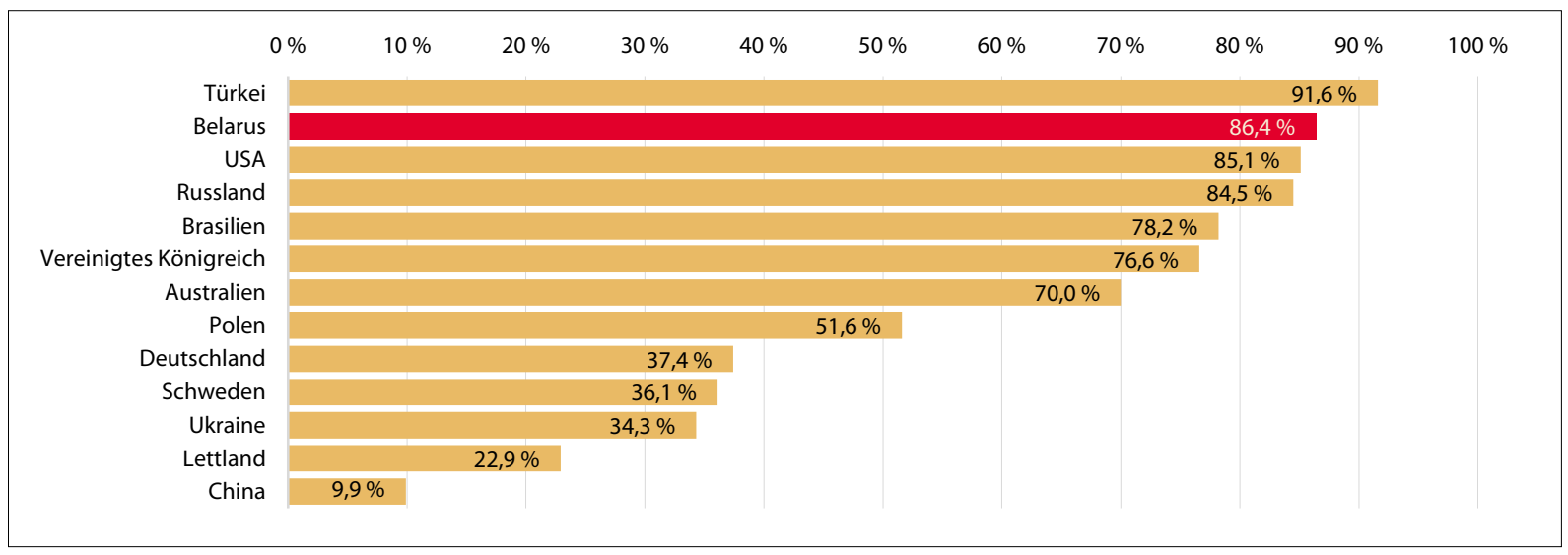

Quelle: International Survey on Coronavirus, https://covid19-survey.org/results.html 
Corona-Epidemie erfolgte auf der Skala »völlig überzogen«, »etwas überzogen«, »angemessen«, »etwas unzureichend« und "völlig unzureichend".

Der Index für eine "unzureichende« Reaktion liegt in Bezug auf die belarussische Regierung bei 0,864 und in Bezug auf die Gesellschaft bei 0,610. Das ergibt hinsichtlich der Regierung den zweiten Platz unter 58 Ländern. Je höher dieser Wert, desto unzureichender ist in der Wahrnehmung die Reaktion der Regierung des betreffenden Landes. Einen höheren Wert weist allein die Türkei auf (0,916). Dichtauf folgen die Vereinigten Staaten $(0,851)$, Russland $(0,845)$ und Indonesien $(0,838)$. Die Belarussen bewerteten also die Wirksamkeit des Vorgehens ihrer Regierung als höchst unzureichend. Das könnte darauf zurückzuführen sein, dass der Weg, den das Land bei der Bekämpfung des Coronavirus eingeschlagen hat (Verzicht auf strenge Quarantäne-Maßnahmen), sich von dem in den Nachbarländern und in anderen Staaten in Europa unterscheidet.

\section{2.}

Gleichzeitig befindet sich die Bewertung dessen, wie die Gesellschaft in Belarus auf die Pandemie reagiert hat, im Rahmen des weltweiten Durchschnitts (Grafik 2). Hier geht es vor allem um die Hilfe, die in der Gesellschaft zum Kampf gegen die Epidemie organisiert wurde (das Sammeln von Geldern, die Beschaffung und Lieferung von Masken, Desinfektionsmitteln und Schutzausrüstung für die Ärzte in den Kliniken). Das wurde in der Gesellschaft schneller organisiert als durch den Staat. Allerdings ließ der Staat nach einer gewissen Zeitspanne natürlich eine entsprechende Produktion anlaufen.

Grafik 2: $\quad$ Anteil der Befragten, die die Reaktion der Gesellschaft als unzureichend wahrnehmen (20.03.06.04.2020; in \%)

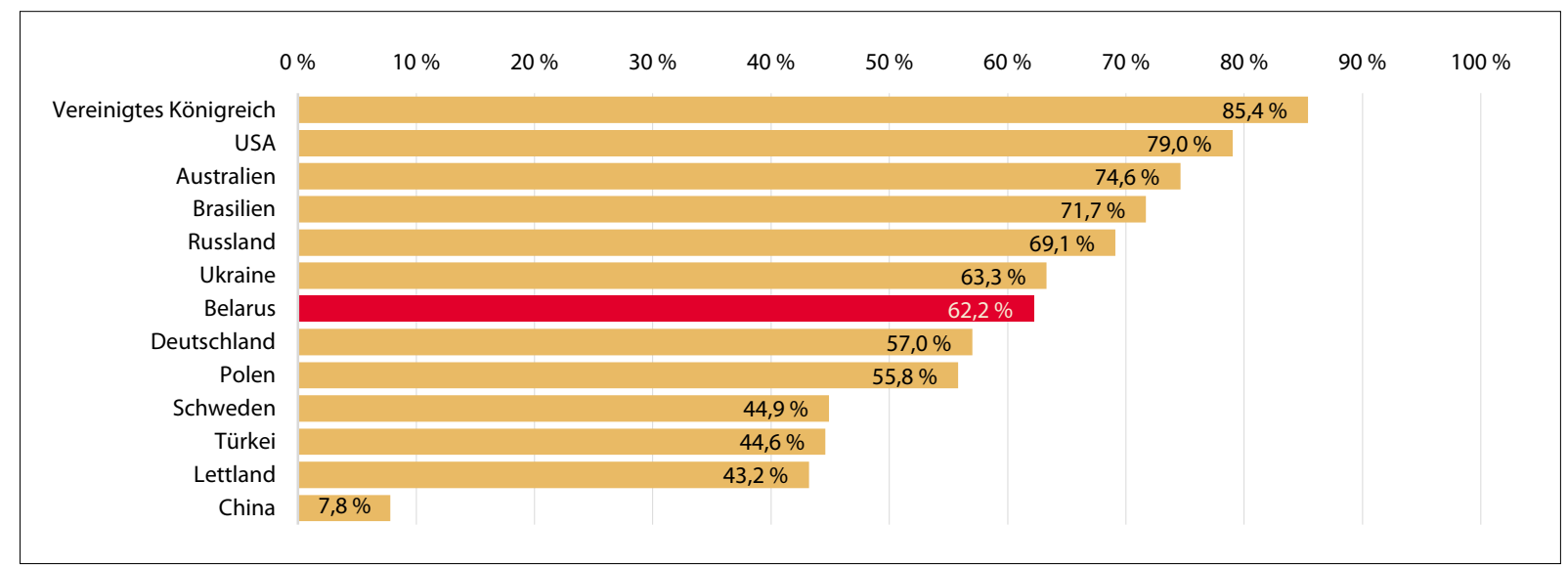

Quelle: International Survey on Coronavirus, https://covid19-survey.org/results.html

Die Reaktion der Gesellschaft - nicht der Regierung - auf die Coronakrise wurde von den Belarussen sehr viel besser bewertet als die Reaktion der Regierung. Dadurch entstand bei den Menschen der Eindruck, dass es die Gesellschaft, und nicht der Staat war, die die Ärzte bei deren heldenhafter, gefährlicher Arbeit unter infektiösen Bedingungen tatsächlich unterstützt hat, und dass es die Gesellschaft war, die den Erkrankten geholfen hat. Tagtäglich erfuhren die Belarussen von Hilfe, die entweder von einer Nichtregierungsorganisation, von einer privaten Firma oder schlichtweg von einer Privatperson geleistet wurde.

Es sei hier betont, dass es nicht nur wichtig ist, die einfache Anzahl der Belarussen zu wissen, die mit der Reaktion ihrer Regierung unzufrieden sind. Um die Spezifik des Geschehens in Belarus zu verstehen, müssen diese Zahlen mit anderen Ländern verglichen werden. Unzufriedene gab es auch in anderen Staaten, unter anderem in hochentwickelten Ländern wie Deutschland oder den USA. In Belarus jedoch ist das Niveau der Unzufriedenheit praktisch das weltweit höchste, was dann im Kontext der Wahlen in Protestverhalten mündete.

3.

Die Beachtung der Regeln des sogenannten epidemiologischen »vermeidenden Handelns (Einhaltung eines Abstands von mindestens zwei Metern) ist ein gesonderter Aspekt, an dem sich die Reaktion der Gesellschaft auf die Pandemie ablesen lässt. Auch hier können wir beobachten, dass Belarus wiederum jenseits des allgemeinen weltweiten Trends 
lag. Zu Beginn der Epidemie hielten sich die Belarussen nur in geringem Maße an dieses Gebot, was auf die inkonsequente Informationspolitik des Staates zurückzuführen ist.

4.

Die offizielle Informationspolitik fand in der Bevölkerung kein Vertrauen. Grafik 3 zeigt das äußerst geringe Vertrauen gegenüber amtlichen Informationen über die Corona-Lage (hinsichtlich der Frage, ob die verbreiteten Informationen stimmen). Wenn wir vom Coronavirus als von einem Zünder für die gegen Lukaschenka gerichteten Stimmungen sprechen, dann sind damit in erster Linie nicht die medizinischen Folgen der Pandemie gemeint, sondern die sozialen und politischen. Das Coronavirus war gleichsam ein magischer Kristall, der vielen Belarussen deutlich gemacht hat, wie unangemessen das System des Staates ist. Die unzureichende Informierung der Bevölkerung bekam nun einen existenziellen Sinn: Die Bevölkerung nicht über eine Verschlechterung ihrer tatsächlichen wirtschaftlichen Lage zu informieren, ist eines. Etwas ganz anders aber ist es, wenn den Menschen in beschnittener, entstellter Form über die Opfer des Coronavirus berichtet wird; das erzeugt eine andere emotionale Ladung. Die Bevölkerung war unzufrieden, mit welcher Frequenz Informationen erfolgten, mit dem Umfang der Informationen und damit, dass die Einschätzung der Zahl der Erkrankten nicht stimmig schien. Die vom Präsidenten in halb scherzhafter Manier vorgeschlagenen Maßnahmen zur Bekämpfung des Virus (»Wodka und Trecker«), und dass er diese äußerst gefährliche Krankheit als Psychose interpretierte, hat die Menschen schlichtweg aufgebracht. Fragen von Leben und Tod erzeugen Motivationen von ganz anderer Kraft als der Rubel, der im Geldbeutel fehlen könnte. Daher kam es lokal zu existenziellen informationellen "Ausbrüchen« - durch Ärzte, die über die schwierige Lage in den Kreiskrankenhäusern berichten, und durch einfache Leute, die von den Opfern in den größeren und kleineren Städten erzählen. Die Menschen sahen um sich herum das eine - die Erkrankten -, und erfuhren aus den staatlichen Medien etwas ganz anderes, nämlich Erfolge der Medizin. Es ist eine Distanz entstanden, eine Kluft zwischen der eigenen, individuellen informationellen Erfahrung der Menschen und dem Bild, das ihnen von den staatlichen Medien vermittelt wird. Wenn dies jedoch früher Routinefragen der wirtschaftlichen Lage betraf, dann ging es jetzt tatsächlich um Fragen von Leben und Tod.

Grafik 3: Anteil der Befragten, die glauben, ihre Regierung habe gelogen (20.03.-06.04.2020; in \%)

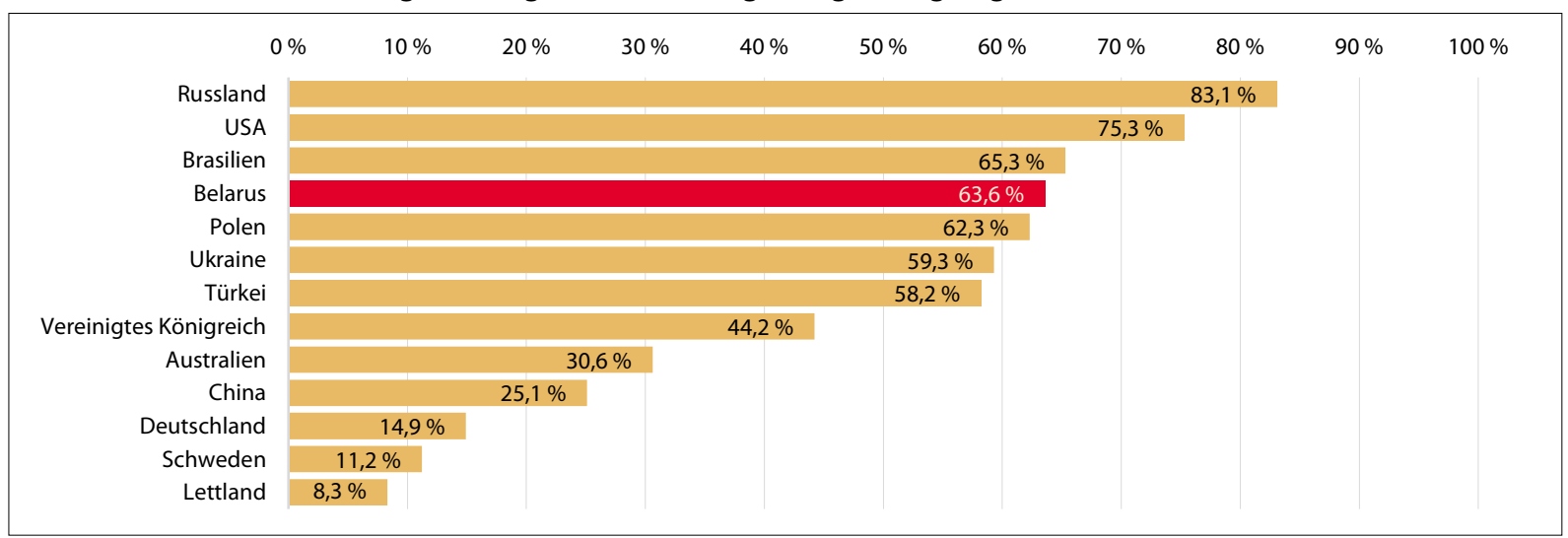

Quelle: International Survey on Coronavirus, https://covid19-survey.org/results.html

Das alles wurde alles durch die Möglichkeit verstärkt, dass die Menschen durch einen Mausklick im Internet Vergleichsinformationen über die Lage in anderen Ländern abrufen können. In der Gesellschaft wurde das schnell als eine Art Parallele zur Informationspolitik der sowjetischen Regierung kurz nach der Tschernobyl-Katastrophe 1986 wahrgenommen, als die sowjetischen Medien den Menschen in Belarus den Unfall und die damit verbundenen Gesundheitsgefahren lange verheimlichten.

Die fehlgeleitete Informationspolitik gegenüber der Bevölkerung wurde durch eine herablassende, erniedrigende Rhetorik in den staatlichen Medien und aus dem Munde des ersten Mannes im Staate ergänzt, was die Reaktionen verstärkte und die Stimmung anheizte: Ein Arzt, der sich bei der Arbeit bei einem Erkrankten angesteckt hat, musste sich anhören, dass er selbst an seiner Infizierung schuld sei, weil er den Abstand nicht eingehalten habe. Und die Angehörigen eines verstorbenen älteren Menschen bekamen die Frage zu hören: Warum ist der überhaupt auf der Straße rumgelaufen? Ohne Mitgefühl für die Opfer des Virus und Respekt für die heldenhafte Arbeit des medizinischen Personals unter diesen Bedingungen. Dieser fehlende Respekt ist in der Tat ein Faktor, der die öffentliche Meinung negativ geladen und aufgeheizt hat. 
Das alles hatte zu Folge, dass sich vor den Wahlen die Motivation zur Stimmabgabe vollkommen verändert hat: Es geht nicht mehr darum, für wen man seine Stimme abgibt, sondern gegen wen. Die Motivation kehrte sich ins Negative: Ich werde nicht dem Kandidaten X meine Stimme geben, der das beste Wirtschaftsprogramm vorlegt; sondern gegen Lukaschenka. Jedem, nur nicht Lukaschenka.

\section{5.}

Der zweite zentrale Grund, der zu der Pandemie hinzukommt und ein derart vehementes Engagement der Wahlaktivisten und diese Unzufriedenheit der Wähler hervorgerufen hat, ist die eigene katastrophale Einschätzung der wirtschaftlichen Lage. Grafik 4 zeigt die negative Entwicklung auf.

Grafik 4: Wie würden Sie die wirtschaftliche Situation in Belarus einschätzen? (in \%)

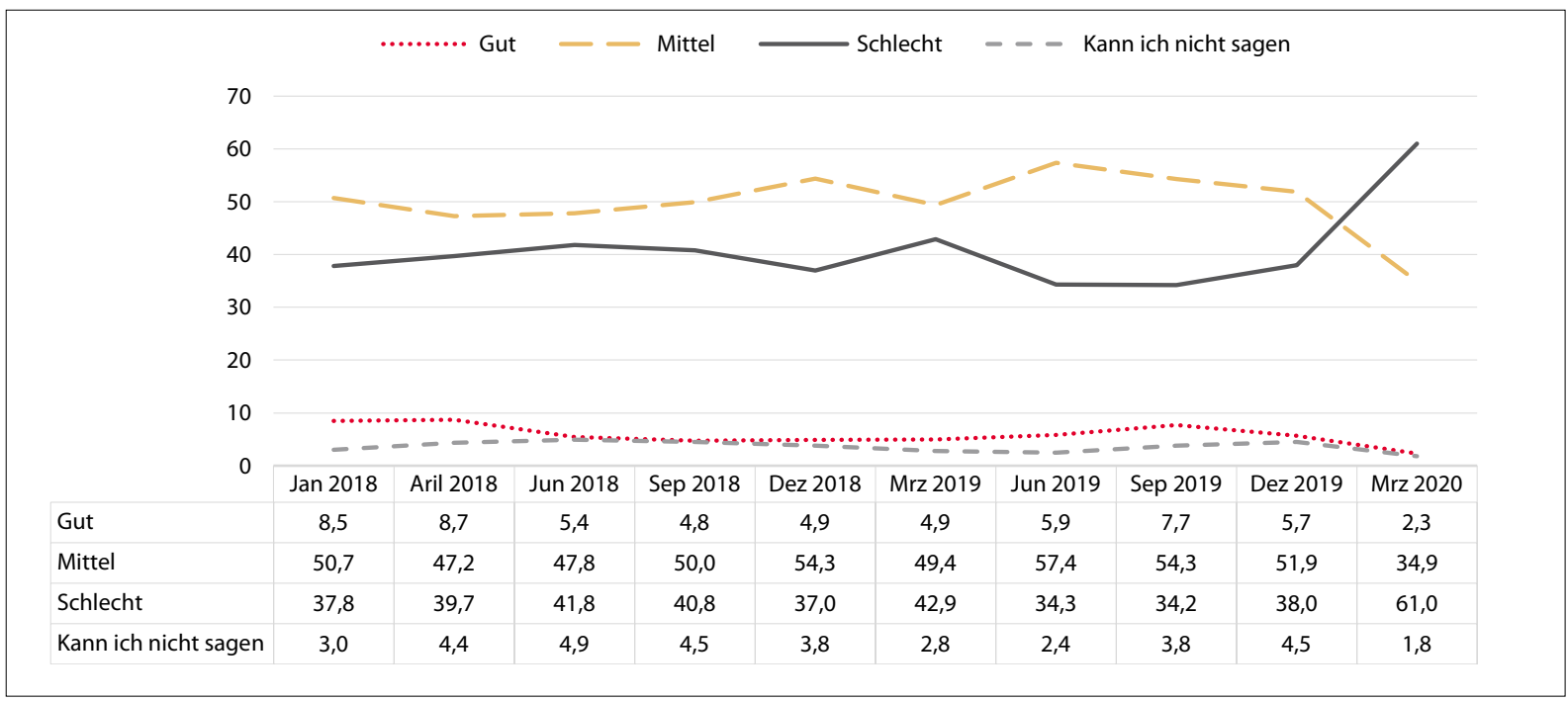

Quelle: Belarusian Analytical Workroom

In den Messungen des Belarusian Analytical Workroom hat es eine derartige Verschlechterung der Werte seit Beginn der 2000er Jahre nicht mehr gegeben. Stellt man einen Vergleich zwischen dem März 2020 (dem Beginn der Pandemie) und dem Dezember 2019 an, so ergibt sich aus Grafik 4, dass die Einschätzung der Makrosituation als "schlecht" von 38 auf 61 Prozent zugenommen hat, was einer Verschlechterung um 23 Prozent entspricht. Das hatte es weder während der Wirtschaftskrisen von 2008, 2011 oder 2015 gegeben, noch in der Zeit der sogenannten "Sozialschmarotzer-Unruhen« des Jahres 2017.

Wichtig ist, dass diese Umfrage bereits vor der massiven Verbreitung des Coronavirus in Belarus begonnen wurde (der Zeitraum erstreckt sich vom 11. März bis zum 6. April). Die Ergebnisse lassen sich als relativ milde betrachten, doch bereits hier zeigen sie eine drastisch gestiegene Unzufriedenheit der Bevölkerung mit ihrer wirtschaftlichen Lage.

Somit haben in Belarus die beiden Faktoren Wirtschaft und Corona-Epidemie im Zusammenspiel die aufgeheizte Atmosphäre vor den Wahlen erzeugt, die von der Weltöffentlichkeit jetzt mit Interesse verfolgt wird.

Übersetzung aus dem Russischen: Hartmut Schröder

Über den Autor

Andrei Vardomatski ist habilitierter Soziologe und seit 1992 Direktor des privaten Meinungsforschungsinstituts »Novak Laboratory«. Er hat den »Belarusian Analytical Workroom» gegründet, leitet seit 1994 Meinungsumfragen, war bzw. ist Leiter soziologischer Projekte zur belarussischen Identität, eines Media Diary als Grundlage für eine Medienplanung in Belarus (1996-2012), Dutzender Forschungsprojekte zu Medienfragen (für die Sender »Voice of America«, BBC und die »Deutsche Welle«), internationaler Projekte zur Erforschung des Wirkung russischer Medien, von Projekte der Europäischen Kommission sowie der Weltbank, sowie Dutzender weiter internationaler Projekte, unter anderem des belarussischen Teils des »International COVID-19 Survey«. Er hält an der Universität Warschau Vorlesungen zu Öffentlicher Meinung und Mediensoziologie. 


\section{Covid-19: Zur Frage der »statistischen Anomalie« in Belarus}

Piotr Rudkouski (Belarussisches Institut für Strategische Studien - BISS, Minsk)

\section{DOI: 10.31205/BA.050.03}

Die erste Infektion mit dem Virus SARS-CoV-2 in Belarus wurde am 28. Februar 2020 festgestellt, exakt einen Monat nachdem in Deutschland der erste Fall bestätigt wurde. Anders als in Deutschland und den übrigen europäischen Staaten beschränkte sich Belarus auf minimale Maßnahmen zur Eindämmung der Pandemie. Am 9. Mai wurde die Parade anlässlich des Tages des Sieges im Zweiten Weltkrieg abgehalten, an der rund 20.000 Menschen teilnahmen. Praktisch alle Einrichtungen arbeiten vollkommen planmäßig, es gab zu keinem Zeitpunkt eine Pflicht, in der Öffentlichkeit Schutzmasken zu tragen.

Gleichzeitig gehört die Sterberate durch CoViD-19 in Belarus - der offiziellen Statistik zufolge - zu den niedrigsten in Europa. Das alles macht den Fall Belarus so besonders, wenn nicht gar einzigartig. Dieser Beitrag unternimmt den Versuch, diesen Fall - genauer gesagt: den Kern der Widersprüche, nämlich die »statistische Anomalie« in Belarus hinsichtlich der Pandemie - möglichst unvoreingenommen zu analysieren.

\section{Antikorona-Maßnahmen: Dreifach milder als in Schweden, bei einer Sterberate wie in Island}

Der belarussische Ansatz zur Bekämpfung der Pandemie ist wohl kaum mit dem in irgendeinem anderen europäischen Land zu vergleichen. Selbst der schwedische Ansatz, der in einer Reihe belarussischer und europäischer Medien als »Absage an Quarantäne« dargestellt wird, muss da im Vergleich zum belarussischen Vorgehen als »strenge Quarantäne« erscheinen. Der Government Response Stringency Index bewertete die Strenge der belarussichen Maßnahmen gegen die Epidemie mit 13,89 von 100 Punkten (Stand: 9. Juni). Gleichzeitig führte der Index die Strenge der Maßnahmen in Schweden mit einem Wert von 46,3 Punkten, also mehr als dreimal so hoch. Im April ist diese Kluft nur unwesentlich geringer gewesen. Im Mai waren die Proportionen ungefähr wie jetzt.

Folgt man der offiziellen Statistik, hat Belarus eine der niedrigsten Sterberaten durch Covid-19 in Europa. Mit Stand vom 11. Juni sind in Belarus lediglich 3,1 Personen pro 100.000 Einwohner an Corona gestorben (in Deutschland waren es 10,6). Noch beeindruckender ist das Verhältnis von registrierten Todesfällen zu den bestätigten Infektionen. Im Laufe des Mai und der ersten Junihälfte schwankte dieser Wert zwischen 0,55 und 0,57 Prozent. Unter den europäischen Ländern kann nur Island einen derart niedrigen Wert vorweisen. Auch die Entwicklung der Sterbezahlen im Zusammenhang mit dem Coronavirus beeindruckt in Belarus. Seit dem 31. März, als der erste Todesfall im Zusammenhang mit Covid-19 registriert wurde, betrug die Anzahl der Sterbefälle im Durchschnitt 3 bis 4 pro Tag (und das bis zum 15. Juni) und überstieg nie 7 Todesfälle pro Tag. Angesichts des Umstandes, dass die Zahl der Todesfälle in Italien, Spanien oder den USA bis an die 2.000 heranreichte, stellt sich die Sterberate in Belarus sehr optimistisch dar. Selbst unter Berücksichtigung der Tatsache, dass die Bevölkerungszahl von Belarus 5 bis 30 Mal geringer ist als in diesen Ländern, so sind die Sterbezahlen durch Covid-19 in Belarus um das 150- bis 300-fache geringer.

Einige Journalisten nichtstaatlicher Medien in Belarus haben dieses statistische Phänomen als »belarussische Anomalie« bezeichnet und behaupten, dass das Gesundheitsministerium die Zahl der Covid-19 Opfer erheblich untertreibt.

Wir sind derzeit nicht in der Lage, diese Behauptung eindeutig zu bestätigen oder zu widerlegen, weswegen wir uns auf Erläuterungen beschränken, und zwar erstens zu den Argumenten, die für eine Fälschung der Statistiken über Coronatote sprechen, und zweitens zu den Argumenten, die auf eine Korrektheit dieser Statistiken hinweisen. Auf Grund dieser Informationen sollen dann einige Schlussfolgerungen gezogen werden.

\section{Wahrscheinlichkeit von Fälschungen - Argumente dafür und dagegen}

Betrachten wir zunächst auf Tabelle 1 zwei Argumentlinien.

Tabelle 1: These und Gegenthese zur Fälschung der Statistiken zur Sterblichkeit durch Covid-19 in Belarus

\begin{tabular}{|l|l|}
\hline $\begin{array}{l}\text { Argumente für die Behauptung, die Statistiken über die Coronatoten in } \\
\text { Belarus würden gefälscht }\end{array}$ & $\begin{array}{l}\text { Argumente für die Behauptung, die Statistiken über die Coronatoten in } \\
\text { Belarus seien korrekt }\end{array}$ \\
\hline $\begin{array}{l}\text { (1) Im belarussischen Staatssystem besteht schon seit langem die } \\
\text { Traditionen eines ideologischen Pressings }\end{array}$ & $\begin{array}{l}\text { (I) In Belarus haben sich die Seuchen- und Gesundheitsschutzbehörden } \\
\text { aus sowjetischer Zeit erhalten und funktionieren relativ gut. }\end{array}$ \\
\hline $\begin{array}{l}\text { (2) Es gibt Insiderberichte, dass die Statistiken über Todesfälle im } \\
\text { Zusammenhang mit Covid-19 nach unten frisiert wurden }\end{array}$ & $\begin{array}{l}\text { (II) Im Land ist die Infrastruktur der Krankenhäuser relativ gut, was auch in } \\
\text { einem WHO-Bericht von 2013 bestätigt wurde. }\end{array}$ \\
\hline $\begin{array}{l}\text { (3) Ein Statistikvergleich: In den meisten anderen Ländern gibt es sehr viel } \\
\text { mehr Sterbefälle im Zusammenhang mit Covid-19 }\end{array}$ & $\begin{array}{l}\text { (III) Die statistische Lebenserwartung in Belarus ist geringer als in den } \\
\text { meisten anderen europäischen Ländern }\end{array}$ \\
\hline & $\begin{array}{l}\text { (IV) Die Praxis, dass zwischen »Tod bei Vorliegen einer Infektion« und »Tod } \\
\text { aufgrund einer Infektion« differenziert wird }\end{array}$ \\
\hline
\end{tabular}


Hier einige Kommentare zu den aufgeführten Argumenten:

$Z u$ (1). Die Liste der Fälle, in denen das System in Belarus aus politischen oder ideologischen Überlegungen heraus Daten über die Wirklichkeit gefälscht hat, ist lang. Das markanteste Beispiel sind die ständigen Wahlfälschungen, die sowohl von unabhängigen belarussischen wie auch von den meisten internationalen Beobachtern festgestellt wurden. Allerdings ist hier ein Aspekt zu berücksichtigen: Die Diagnostik hinsichtlich der Todesursachen unterscheidet sich erheblich von der Untersuchung, ob es bei der Stimmauszählung zu Manipulationen gekommen ist oder nicht. Um etwa festzustellen ob ein Stimmzettel, auf dem ein »alternativer" Kandidat angekreuzt ist, bei der Stimmauszählung auf dem Stapel der Stimmen für Aljaksandr Lukaschenka landet, braucht es keine speziellen Kenntnisse oder komplexen Analysemethoden. Bei der Feststellung der Todesursache hingegen sind gewisse Kenntnisse, bestimmte Analysen und Zeit erforderlich.

$Z u$ (2). Da es sich um mehr als nur vereinzelte Berichte über frisierte Statistiken handelt (die unter anderem über Medien, soziale Netzwerke und persönliche Kontakte verbreitet werden) spricht die Gesamtheit dieser Berichte für eine hohe Wahrscheinlichkeit, dass manipuliert wird. Da Covid-19 starke Emotionen hervorruft, ist allerdings zu berücksichtigen, dass auch übertriebene Darstellungen möglich sind.

$Z u$ (3). Die Stärke dieses Arguments beruht auf zwei Annahmen, nämlich dass a) die Statistiken über Coronatote in den meisten anderen Ländern stimmen und b) es in Belarus keinerlei Faktoren gibt, die hier zu einer geringeren Sterblichkeit durch Covid-19 führen. Beide Annahmen sind nicht eindeutig zu verifizieren. Selbst wenn man davon ausgeht, dass es in den meisten anderen Ländern keine vorsätzliche Manipulation der Statistik im Sinne einer höheren Zahl von Coronatoten gibt, lässt sich gleichwohl nicht ausschließen, dass es zu gewöhnlichen kognitiven Verzerrungen kommt. Da allenthalben eine starke Nachfrage nach schneller und eindeutiger Information über die Pandemie herrscht, könnte sich die Diagnose der Tode durch Covid-19 in Richtung einer überhöhten Zahl der betreffenden Sterbefälle verzerren.

Der Aspekt (b) wird unter der Erörterung der Argumente des zweiten Blocks erläutert, nämlich zugunsten einer Stimmigkeit der belarussischen Statistik.

$Z u$ (I). In Belarus sind die Seuchen- und Gesundheitsschutzbehörden aus sowjetischer Zeit erhalten geblieben. Das ist womöglich einer der wenigen positiven Aspekte des Festhaltens an sowjetischen Traditionen durch das belarussische Regime. Angesichts der Pandemie könnte dies hinsichtlich der geringen Zahl an Coronatoten eine positive Rolle gespielt haben.

$Z u$ (II). In dem Bericht der Weltgesundheitsorganisation WHO von 2013 ist zu lesen: „Belarus verfügte $2011 \mathrm{im}$ europäischen Bereich der WHO mit über die höchste Anzahl an Krankenhausbetten pro Kopf, nämlich über 11,3 pro 1.000 Einwohner, was deutlich über dem Durchschnitt in der GUS [Gemeinschaft Unabhängiger Staaten] mit 8,3 pro $1.000 \mathrm{im} \mathrm{Jahr} 2011$ und in der EU mit 5,5 pro 1.000 Einwohner (2010) liegt." Wir gehen davon aus, dass sich die Zahl der Krankenhausbetten in den vergangenen neun Jahren nicht wesentlich verringert hat.

$Z u$ (III). Aus dem Bericht des Nationalen Instituts für das Gesundheitswesen in Italien (Istituto superiore di sanità) vom 22. Mai geht hervor, dass das Durchschnittsalter der an Covid-19 gestorbenen Personen 81 Jahre beträgt. Das sind zwar Daten aus nur einem Land, doch bieten sie eine Grundlage für die Annahme, dass die altersbezogene Demographie einer der wichtigen Faktoren für die Sterblichkeit durch Covid-19 sein könnte: Je größer die Altersgruppe der über Achtzigjährigen, desto höher die Sterbezahlen durch Covid-19.

Dem Bericht des Entwicklungsprogramms der Vereinten Nationen von 2019 zufolge liegt Belarus bei der statistischen Lebenserwartung an 82. Stelle (bei 186 Ländern): In Belarus beträgt die Lebenserwartung 74,6 Jahre (in Deutschland liegt sie bei 81,2 Jahren, in Schweden bei 82,7 und in Italien bei 83,6 Jahren - siehe: Human Development Report 2019. United Nations Development Programme. 10. Dezember 2019).

Die relativ geringe Lebenserwartung ist zweifelsohne kaum etwas, mit dem sich das Land brüsten könnte, und sie verweist auf eine Reihe sozialer und wirtschaftlicher Probleme. Im Kontext der »statistischen Anomalie« jedoch könnte sie zum Teil eine Erklärung sein, warum die Zahl der Coronatoten in Belarus geringer ausfällt als in vielen anderen Ländern.

$Z u(I V)$. Bei der Diskussion über die Sterblichkeit durch die Pandemie wird immer wieder die Frage nach der Ursächlichkeit aufgeworfen. Wie bereits erwähnt, ergibt sich bei der Feststellung einer Kausalität zwischen einer Infektion im Organismus und einem Todesfall eine »Grauzone der Ungewissheit«, also eine Situation, in der keine eindeutige Antwort gegeben werden kann, ob ein Patient durch eine Infektion oder mit einer Infektion gestorben ist. Bei dieser Argumentation ist der logische Fehler Namens post hoc ergo propter hoc (wörtlich: nach etwas, also durch etwas) wohlbekannt. Dieser besteht in der unbegründeten Annahme, dass in dem Falle, dass ein Ereignis F nach einem Ereignis $\mathrm{G}$ erfolgt, dies automatisch bedeutet, $\mathrm{G}$ sei die Ursache von F. 
Die Frage, wie die verschiedenen Länder das Problem dieser Grauzone lösen, in welchem Maße dieser systematische post hoc-Irrtum zum Tragen kommt und auf welche Weise dies Einfluss auf die Statistik hat, erfordert weitere Untersuchungen. Bisweilen beschränken wir uns auf den Hinweis, dass das belarussische Gesundheitsministerium so ergibt es sich aus den Erklärungen von Vertretern des Ministeriums - bestrebt ist, zwischen Todesfällen mit SARSCoV-2 und solchen durch SARS-CoV-2 zu differenzieren. Natürlich bleibt die Frage, ob eine solche Differenzierung nicht mit unterschiedlichen Fehlern und Verzerrungen behaftet ist. Allerdings stellt sich diese Frage auch in jenen Ländern, in denen eine solche Differenzierung überhaupt nicht vorgenommen wird.

\section{Vorläufige Schlussfolgerungen}

Nach einer Analyse der Argumente für die widerstreitenden Behauptungen ist festzustellen, dass die Frage, ob es in Belarus eine Manipulation der Corona-Statistiken gibt oder nicht, bislang nicht eindeutig zu beantworten ist. In unserem Institut, dem BISS, verfolgen wir derzeit die Arbeitshypothese, dass es in der Tat eine ideologische "Korrektur" der Statistik gibt. Das heißt, wir sind nicht der Ansicht, dass die Zahl der Coronatoten um das Fünf- bis Zahnfache nach unten manipuliert wurde, wie das in einigen oppositionellen belarussischen Medien behauptet wird.

Natürlich ist jede vorsätzliche Verzerrung der tatsächlichen Verhältnisse abzulehnen, umso mehr, wenn es um eine so lebenswichtige Frage geht. Wenn man jedoch von dem ethischen Aspekt des Problems abstrahiert und sich der zutiefst faktenbezogenen Frage widmet, wie sehr die offizielle Statistik von der Wirklichkeit entfernt ist, so lautet die Antwort wohl: im Rahmen der kognitiven Fehlerspanne. Die Abweichung von der Wirklichkeit kann beträchtlich sein, in Belarus wie auch in anderen Ländern. Diese Abweichung kann sich jedoch aus einem ganz banalen Umstand ergeben: Die kognitiven Möglichkeiten des Menschen sind nicht unbegrenzt.

Übersetzung aus dem Russischen: Hartmut Schröder

\section{Über den Autor}

Piotr Rudkouski ist Direktor des Belarussischen Instituts für Strategische Studien (BISS) und Koordinator des Projekts »Covid in Belarus. Optimale Lösungen in einer ungewissen Lage«. Seine Forschungsinteresse gilt der Wertetransformation, Risikoanalysen und kritischem Denken.

\section{Bibliographie}

- Rudkouski, Piotr: 70 Days without a Lockdown. Belarus' Special Path in the Fight against CoViD-19 [=BISS CovidResearch Nr. 1], BISS, 22. Mai 2020; https://belinstitute.com/sites/biss.newmediahost.info/files/attachedfiles/2020-6-2\%2070\%20Days\%20without\%20a\%20Lockdown.pdf

- Vitushka, Andrei; Rudkouski, Piotr: Herd Immunity or Death? Neither. [=BISS CovidResearch Nr. 2], BISS, 16. Juni 2020; https://belinstitute.com/sites/biss.newmediahost.info/files/attached-files/2020-6-16\%20Herd\%20 Immunity\%20or\%20Death.\%20Neither.pdf. 


\section{Covid-19 in Belarus im Vergleich}

Grafik 1: Bestätigte Covid-19-Fälle pro 1 Mio. Personen (Stand: 1. Juli 2020)

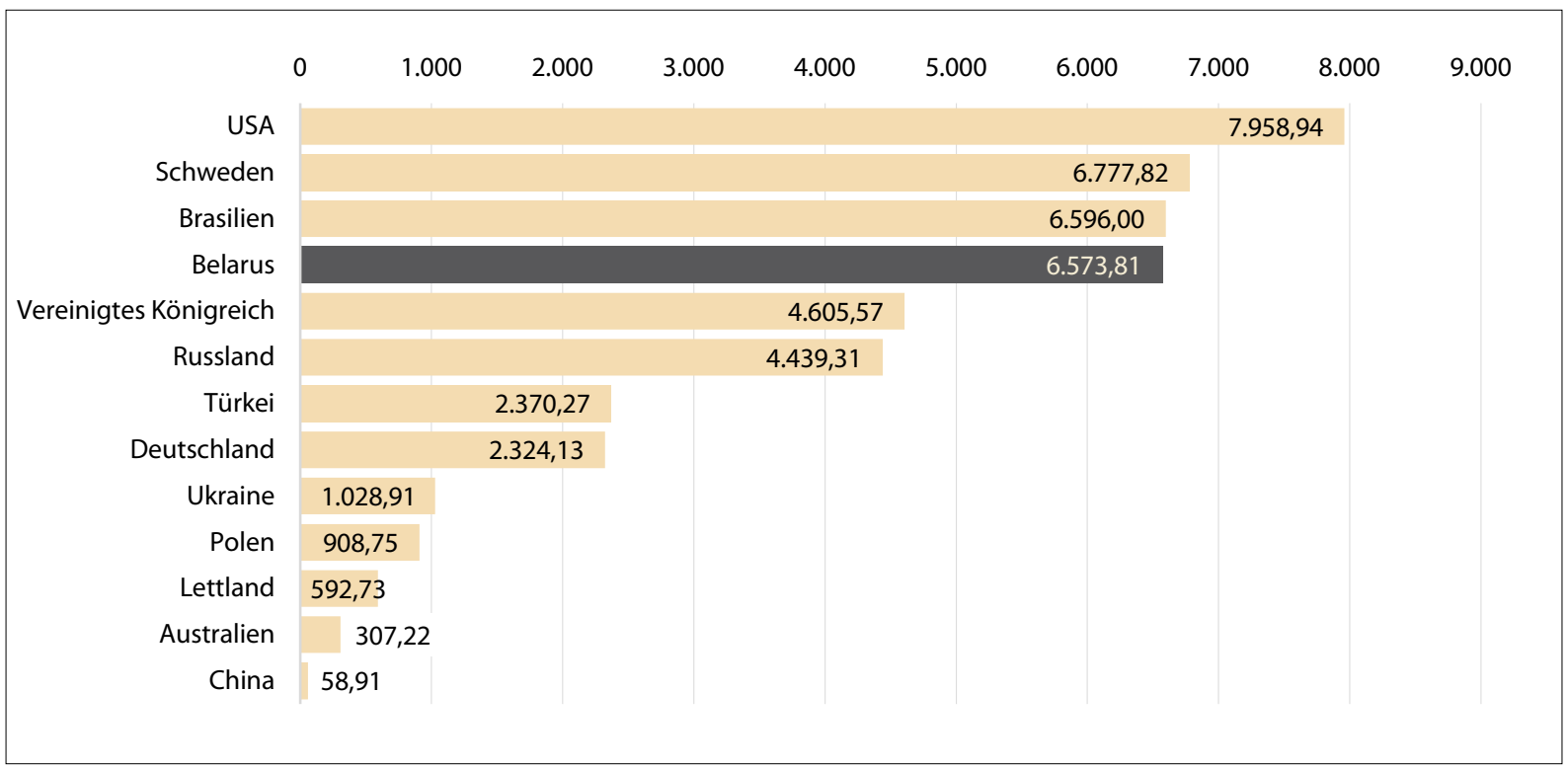

Quelle: Total confirmed COVID-19 cases per million people, https://ourworldindata.org/covid-cases

Grafik 2: Bestätigte Covid-19-Todesfälle pro 1 Mio. Personen (Stand: 1. Juli 2020)

\begin{tabular}{|c|c|c|c|c|c|c|}
\hline & 100 & 200 & 300 & 400 & 600 & 700 \\
\hline Vereinigtes Königreich & & & & & 644,17 & \\
\hline Schweden & & & & 528,06 & & \\
\hline USA & & & 384,92 & & & \\
\hline Brasilien & & 280,36 & & & & \\
\hline Deutschland & 107,24 & & & & & \\
\hline Russland & 63,86 & & & & & \\
\hline Türkei & 60,84 & & & & & \\
\hline Belarus & 41,48 & & & & & \\
\hline Polen & 38,66 & & & & & \\
\hline Ukraine & 26,82 & & & & & \\
\hline Lettland & 15,9 & & & & & \\
\hline Australien & 4,08 & & & & & \\
\hline China & 3,22 & & & & & \\
\hline
\end{tabular}

Quelle:Total confirmed COVID-19 deaths per million people, https://ourworldindata.org/coronavirus-data 
Grafik 3: Todesfallrate der Covid-19-Pandemie (in \% der bestätigten Infizierten; Stand: 1. Juli 2020)

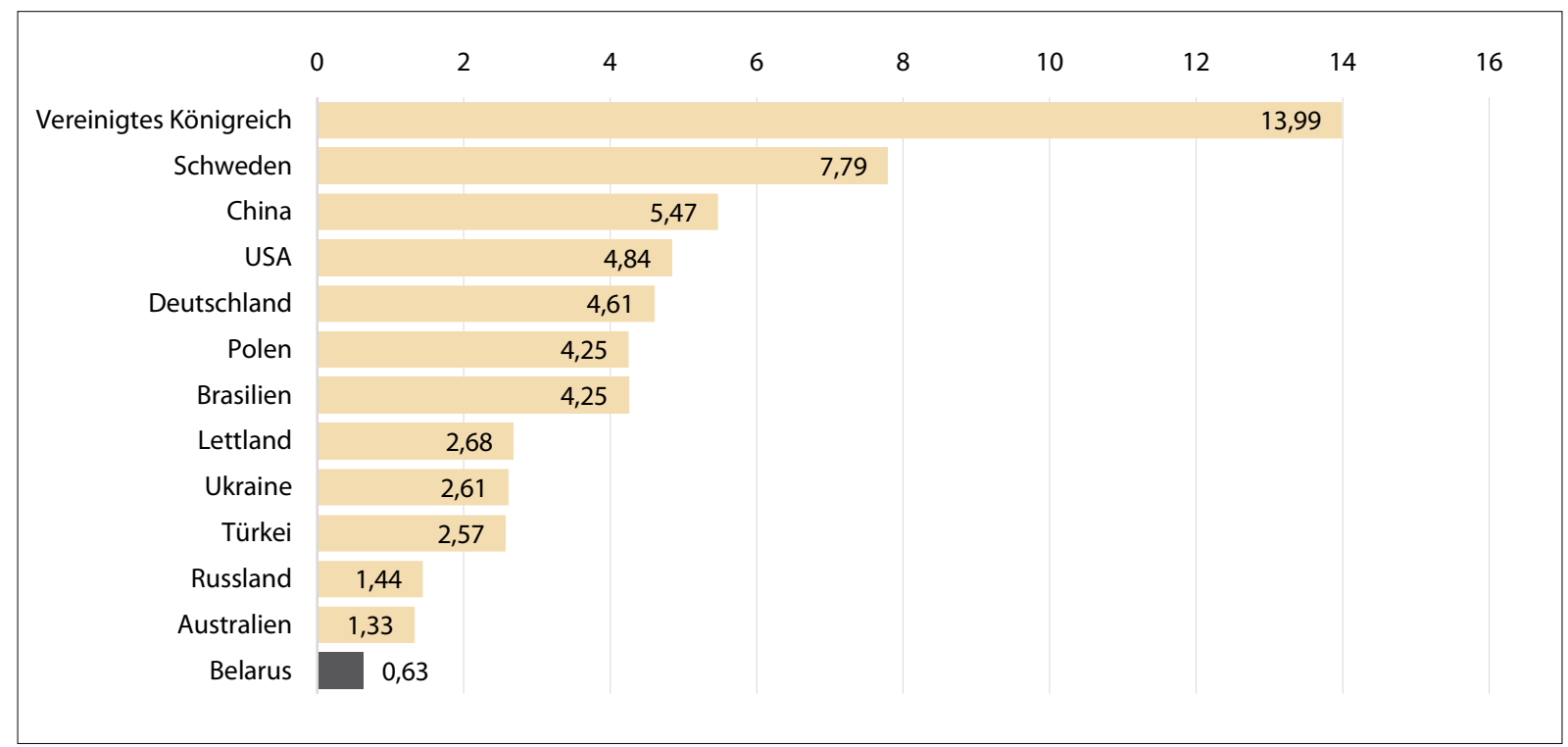

Quelle: Case fatality rate of the ongoing COVID-19 pandemic, https://ourworldindata.org/mortality-risk-covid

Grafik 4: Covid-19 Tests pro 1.000 Personen (Stand: 1. Juli 2020)

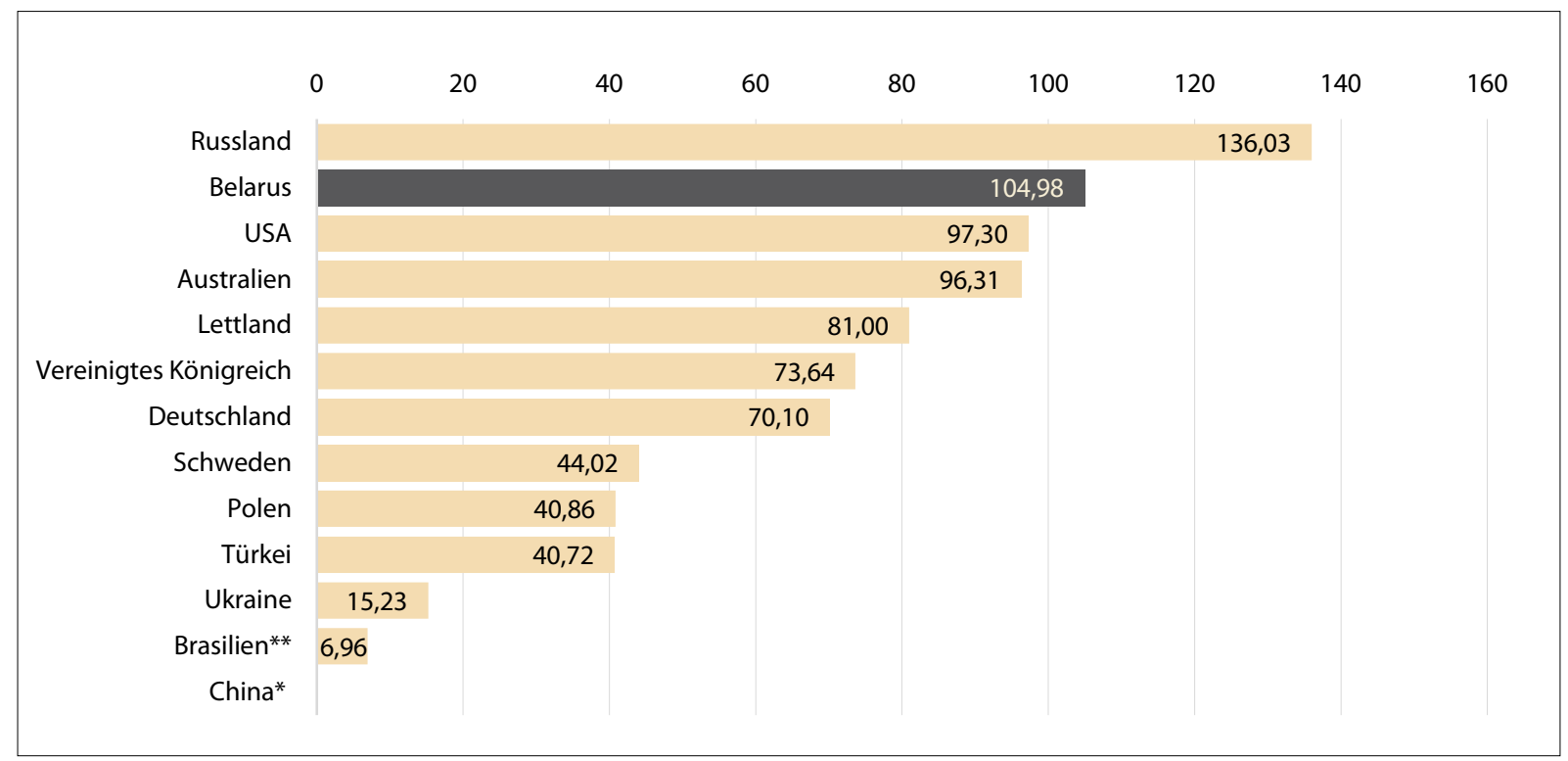

* keine Daten ** Stand: 30 . Juni 2020

Quelle: Total COVID-19 tests per 1,000 people, https://ourworldindata.org/coronavirus-data 
Grafik 5: Covid-19 Government Response Stringency Index* (Stand: 30. Juni 2020)

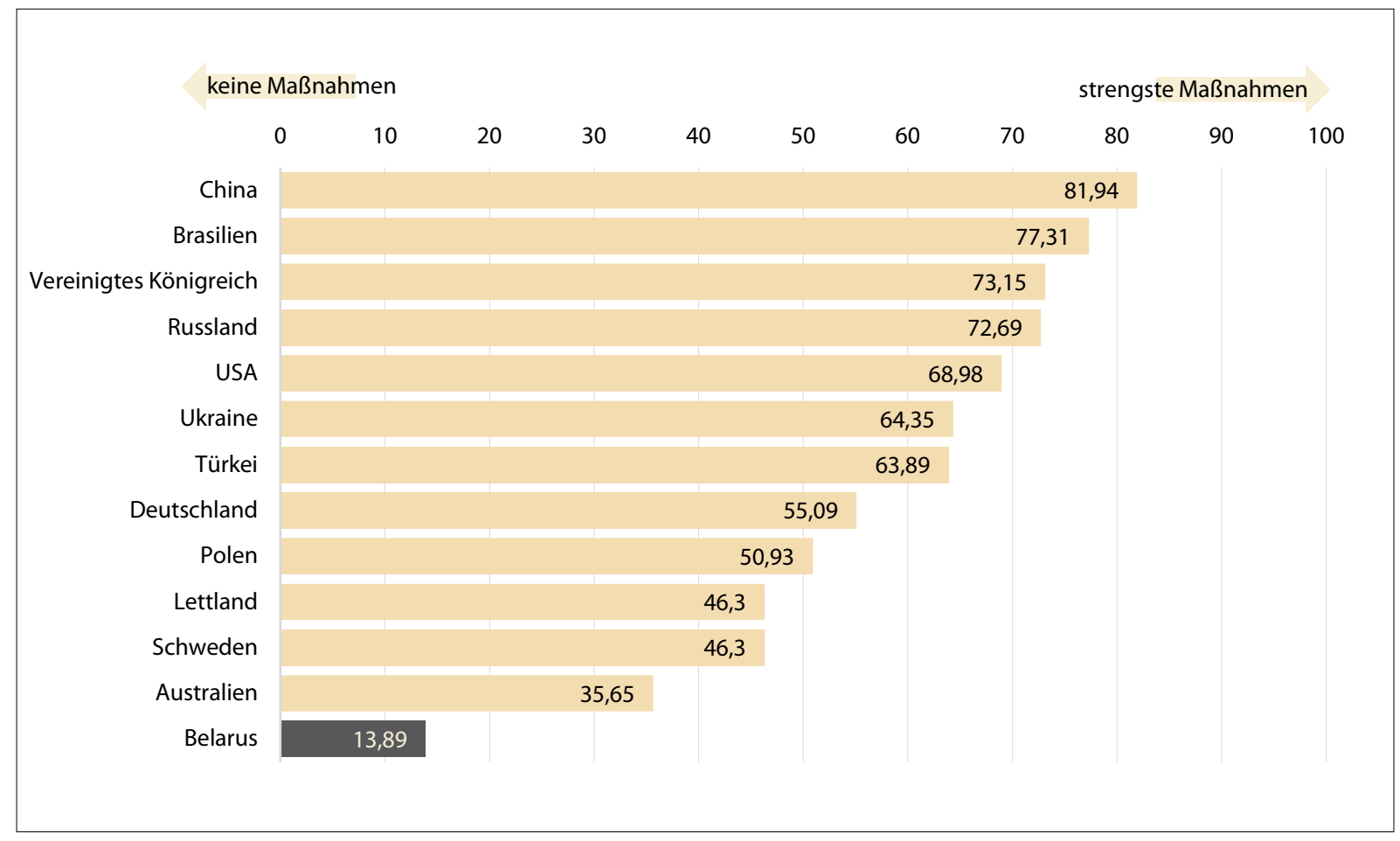

*O (keine Maßnahmen) bis 100 (am strengsten)

Quelle: COVID-19: Government Response Stringency Index, https://ourworldindata.org/policy-responses-covid

Grafik 6: Krankenhausbetten pro 1.000 Personen

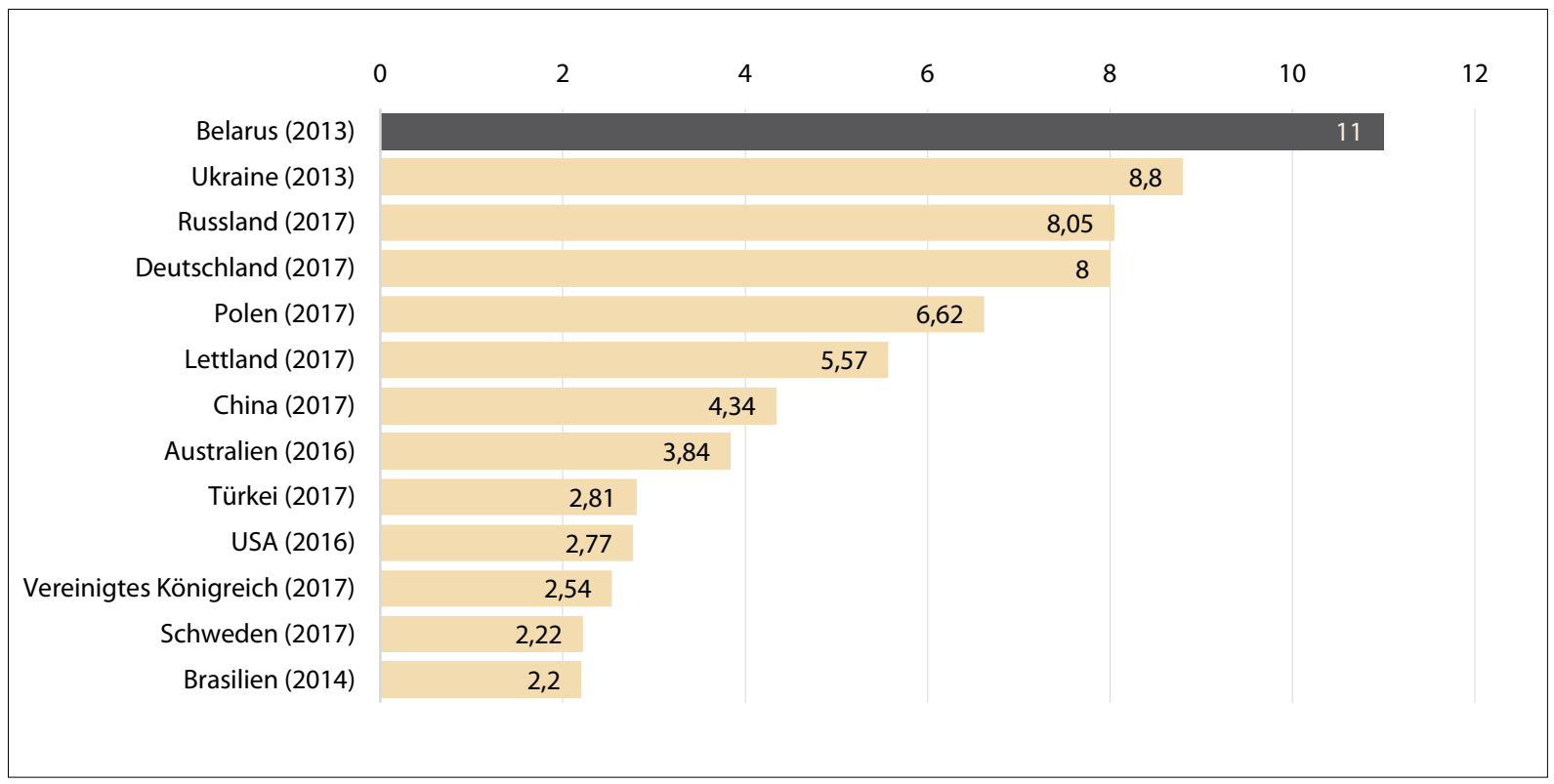

Quelle: Hospital beds per 1,000 people, https://ourworldindata.org/grapher/hospital-beds-per-1000-people 
Grafik 7: $\quad$ Ausbreitung von Covid-19 im Vergleich (Fälle pro 100.000 Einwohner, 1. März - 7. Juli 2020)

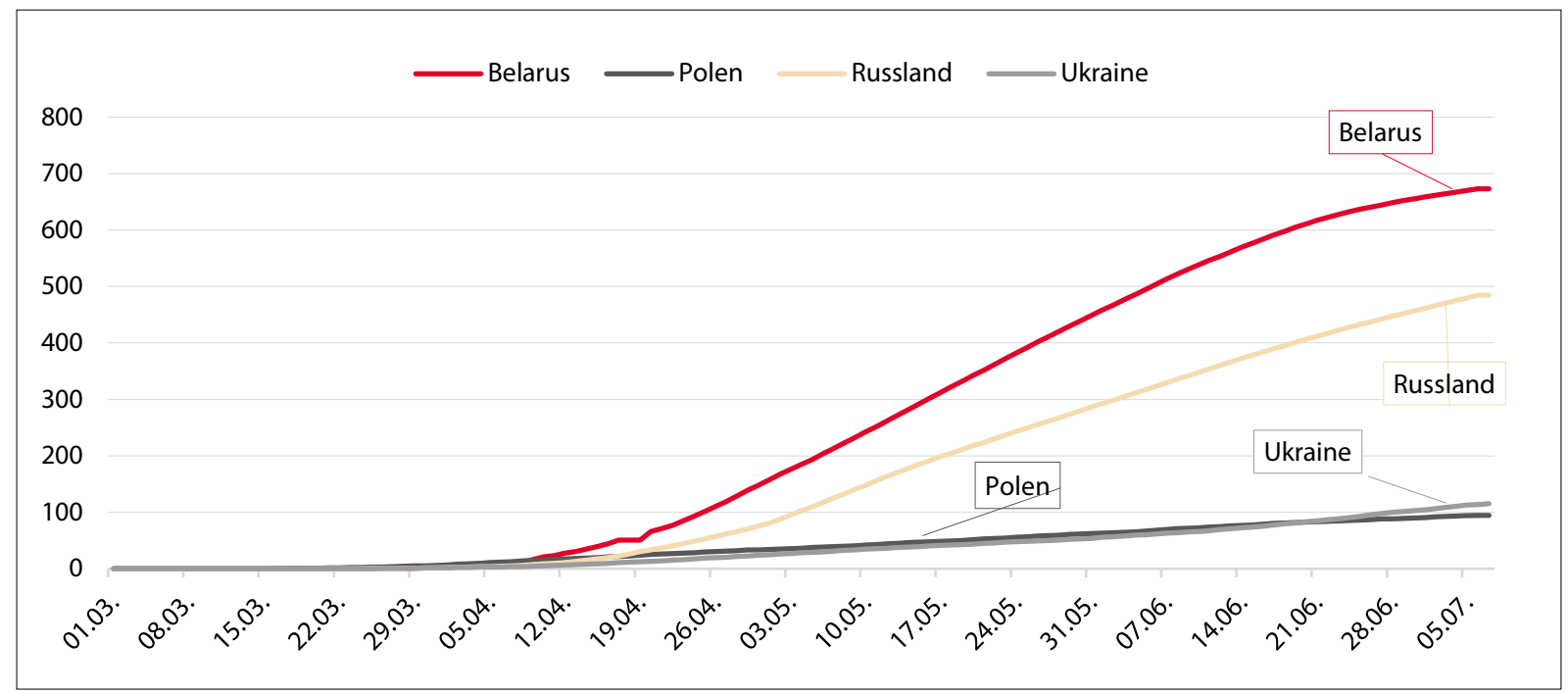

Auch wenn die Zahlen alle aus einer Quelle stammen, sind sie nur begrenzt vergleichbar, da sich zwischen den Ländern der Umfang der Tests und die Erfassung von Covid-19 als Todesursache teilweise deutlich unterscheiden.

Quelle: Johns Hopkins Universität. Stand: 07.07.2020. 09:33 Uhr MESZ https://coronavirus.jhu.edu/map.html; https://github.com/CSSEGISandData/COVID-19/ blob/master/csse_covid_19_data/csse_covid_19_time_series/time_series_covid19_confirmed_global.csv; Einwohnerzahlen: CIA World Factbook, https:// www.cia.gov/library/publications/the-world-factbook/

Tabelle 1: Ausbreitung von Covid-19 im Vergleich (Fälle insgesamt, 12. April - 7. Juli 2020)

\begin{tabular}{|c|c|c|c|c|}
\hline Datum & Belarus & Polen & Russland & Ukraine \\
\hline 12.04. & 2.578 & 6.674 & 15.770 & 2.777 \\
\hline 13.04. & 2.919 & 6.934 & 18.328 & 3.102 \\
\hline 14.04. & 3.281 & 7.202 & 21.102 & 3.372 \\
\hline 15.04. & 3.728 & 7.582 & 24.490 & 3.764 \\
\hline 16.04. & 4.204 & 7.918 & 27.938 & 4.161 \\
\hline 17.04. & 4.779 & 8.379 & 32.008 & 4.662 \\
\hline 18.04. & 4.779 & 8.742 & 36.793 & 5.106 \\
\hline 19.04. & 4.779 & 9.287 & 42.853 & 5.449 \\
\hline 20.04. & 6.264 & 9.593 & 47.121 & 5.710 \\
\hline 21.04. & 6.723 & 9.856 & 52.763 & 6.125 \\
\hline 22.04. & 7.281 & 10.169 & 57.999 & 6.592 \\
\hline 23.04. & 8.022 & 10.511 & 62.773 & 7.170 \\
\hline 24.04. & 8.773 & 10.892 & 68.622 & 7.647 \\
\hline 25.04. & 9.590 & 11.273 & 74.588 & 8.125 \\
\hline 26.04. & 10.463 & 11.617 & 80.949 & 8.617 \\
\hline 27.04. & 11.289 & 11.902 & 87.147 & 9.009 \\
\hline 28.04. & 12.208 & 12.218 & 93.558 & 9.410 \\
\hline 29.04. & 13.181 & 12.640 & 99.399 & 9.866 \\
\hline 30.04. & 14.027 & 12.877 & 106.498 & 10.406 \\
\hline 01.05. & 14.917 & 13.105 & 114.431 & 10.861 \\
\hline 02.05. & 15.828 & 13.375 & 124.054 & 11.411 \\
\hline 03.05. & 16.705 & 13.693 & 134.687 & 11.913 \\
\hline 04.05. & 17.489 & 14.006 & 145.268 & 12.331 \\
\hline 05.05. & 18.350 & 14.431 & 155.370 & 12.697 \\
\hline 06.05. & 19.255 & 14.740 & 165.929 & 13.184 \\
\hline 07.05. & 20.168 & 15.047 & 177.160 & 13.691 \\
\hline 08.05. & 21.101 & 15.366 & 187.859 & 14.195 \\
\hline 09.05. & 22.052 & 15.651 & 198.676 & 14.710 \\
\hline 10.05. & 22.973 & 15.996 & 209.688 & 15.232 \\
\hline & & & & \\
\hline
\end{tabular}

\begin{tabular}{|c|c|c|c|c|}
\hline Datum & Belarus & Polen & Russland & Ukraine \\
\hline 11.05. & 23.906 & 16.326 & 221.344 & 15.648 \\
\hline 12.05 & 24.873 & 16.921 & 232.243 & 16.023 \\
\hline 13.05 & 25.825 & 17.204 & 242.271 & 16.425 \\
\hline 14.05. & 26.772 & 17.615 & 252.245 & 16.847 \\
\hline 15.05 & 27.730 & 18.016 & 262.843 & 17.330 \\
\hline 16.05 & 28.681 & 18.257 & 272.043 & 17.858 \\
\hline 17.05 & 29.650 & 18.529 & 281.752 & 18.291 \\
\hline 18.05 & 30.572 & 18.885 & 290.678 & 18.616 \\
\hline 19.05. & 31.508 & 19.268 & 299.941 & 18.876 \\
\hline 20.05 & 32.426 & 19.739 & 308.705 & 19.230 \\
\hline 21.05 & 33.371 & 20.143 & 317.554 & 19.706 \\
\hline 22.05 & 34.303 & 20.619 & 326.448 & 20.148 \\
\hline 23.05 & 35.244 & 20.931 & 335.882 & 20.580 \\
\hline 24.05. & 36.198 & 21.326 & 344.481 & 20.986 \\
\hline 25.05 & 37.144 & 21.631 & 353.427 & 21.245 \\
\hline 26.05 & 38.059 & 22.074 & 362.342 & 21.584 \\
\hline 27.05 & 38.956 & 22.473 & 370.680 & 21.905 \\
\hline 28.05 & 39.858 & 22.825 & 379.051 & 22.382 \\
\hline 29.05 & 40.764 & 23.155 & 387.623 & 22.811 \\
\hline 30.05 & 41.658 & 23.571 & 396.575 & 23.204 \\
\hline 31.05. & 42.556 & 23.786 & 405.843 & 23.672 \\
\hline 01.06. & 43.403 & 24.165 & 414.328 & 24.562 \\
\hline 02.06 & 44.255 & 24.395 & 423.186 & 24.895 \\
\hline 03.06. & 45.116 & 24.687 & 431.715 & 25.385 \\
\hline 04.06. & 45.981 & 25.048 & 440.538 & 25.981 \\
\hline 05.06. & 46.868 & 25.410 & 449.256 & 26.542 \\
\hline 06.06. & 47.751 & 25.986 & 458.102 & 27.101 \\
\hline 07.06 & 48.630 & 26.561 & 467.073 & 27.599 \\
\hline 08.06. & 49.453 & 27.160 & 476.043 & 28.077 \\
\hline
\end{tabular}


Tabelle 1: Ausbreitung von Covid-19 im Vergleich (Fälle, 12. April - 7. Juli 2020) (Fortsetzung)

\begin{tabular}{|c|c|c|c|c|}
\hline Datum & Belarus & Polen & Russland & Ukraine \\
\hline 09.06. & 50.265 & 27.560 & 484.630 & 28.479 \\
\hline 10.06. & 51.066 & 27.842 & 493.023 & 29.015 \\
\hline 11.06. & 51.816 & 28.201 & 501.800 & 29.706 \\
\hline 12.06. & 52.520 & 28.577 & 510.761 & 30.415 \\
\hline 13.06. & 53.241 & 29.017 & 519.458 & 31.177 \\
\hline 14.06. & 53.973 & 29.392 & 528.267 & 31.851 \\
\hline 15.06. & 54.680 & 29.788 & 536.484 & 32.536 \\
\hline 16.06. & 55.369 & 30.195 & 544.725 & 33.209 \\
\hline 17.06. & 56.032 & 30.701 & 552.549 & 33.986 \\
\hline 18.06. & 56.657 & 31.015 & 560.321 & 34.833 \\
\hline 19.06. & 57.333 & 31.316 & 568.292 & 35.755 \\
\hline 20.06. & 57.936 & 31.620 & 576.162 & 36.615 \\
\hline 21.06. & 58.505 & 31.931 & 583.879 & 37.361 \\
\hline 22.06. & 59.023 & 32.227 & 591.465 & 38.056 \\
\hline 23.06. & 59.487 & 32.527 & 598.878 & 38.901 \\
\hline
\end{tabular}

\begin{tabular}{|c|c|c|c|c|}
\hline Datum & Belarus & Polen & Russland & Ukraine \\
\hline 24.06. & 59.945 & 32.821 & 606.043 & 39.852 \\
\hline 25.06. & 60.382 & 33.119 & 613.148 & 40.854 \\
\hline 26.06. & 60.713 & 33.395 & 619.936 & 41.975 \\
\hline 27.06. & 61.095 & 33.714 & 626.779 & 42.932 \\
\hline 28.06. & 61.475 & 33.907 & 633.563 & 43.856 \\
\hline 29.06. & 61.790 & 34.154 & 640.246 & 44.538 \\
\hline 30.06. & 62.118 & 34.393 & 646.929 & 45.254 \\
\hline 01.07. & 62.424 & 34.775 & 653.479 & 45.924 \\
\hline 02.07. & 62.698 & 35.146 & 660.231 & 46.821 \\
\hline 03.07. & 62.997 & 35.405 & 666.941 & 47.705 \\
\hline 04.07. & 63.270 & 35.719 & 673.564 & 48.628 \\
\hline 05.07. & 63.554 & 35.950 & 680.283 & 49.468 \\
\hline 06.07. & 63.804 & 36.155 & 686.852 & 50.053 \\
\hline 07.07. & 63.804 & 36.155 & 686.852 & 50.617 \\
\hline
\end{tabular}

Für die Zahlen vom 01.03.-11.04.2020, siehe Belarus-Analysen Nr. 48, S. 8.

Auch wenn die Zahlen alle aus einer Quelle stammen, sind sie nur begrenzt vergleichbar, da sich zwischen den Ländern der Umfang der Tests und die Erfassung von Covid-19 als Todesursache teilweise deutlich unterscheiden.

Quelle: Johns Hopkins Universität. Stand: 07.07.2020. 09:33 Uhr MESZ https://coronavirus.jhu.edu/map.html; https://github.com/CSSEGISandData/COVID-19/ blob/master/csse_covid_19_data/csse_covid_19_time_series/time_series_covid19_confirmed_global.csv

\section{Grafik 8: $\quad$ Todesfälle durch Covid-19 im Vergleich (Todesfälle pro 100.000 Einwohner, 1. März - 7. Juli 2020)}

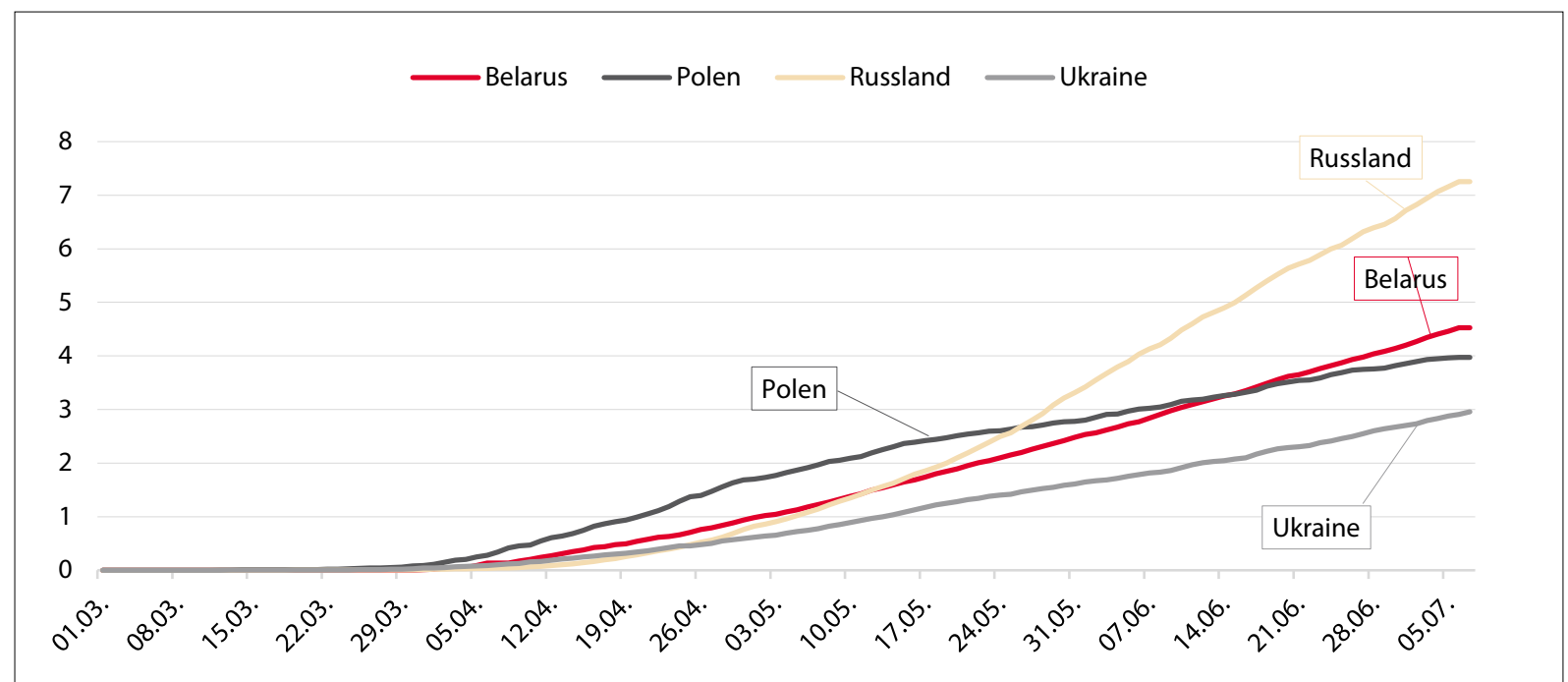

Auch wenn die Zahlen alle aus einer Quelle stammen, sind sie nur begrenzt vergleichbar, da sich zwischen den Ländern der Umfang der Tests und die Erfassung von Covid-19 als Todesursache teilweise deutlich unterscheiden.

Quelle: Johns Hopkins Universität. Stand: 07.07.2020. 09:33 Uhr MESZ https://coronavirus.jhu.edu/map.html; https://github.com/CSSEGISandData/COVID-19/ blob/master/csse_covid_19_data/csse_covid_19_time_series/time_series_covid19_deaths_global.csv; Einwohnerzahlen:CIA World Factbook, https://www. cia.gov/library/publications/the-world-factbook/ 
Tabelle 2: $\quad$ Todesfälle durch Covid-19 im Vergleich (12. April - 7. Juli 2020)

\begin{tabular}{|c|c|c|c|c|}
\hline Datum & Belarus & Polen & Russland & Ukraine \\
\hline 12.04 & 26 & 232 & 130 & 83 \\
\hline 13.04. & 29 & 245 & 148 & 93 \\
\hline 14.04. & 33 & 263 & 170 & 98 \\
\hline 15.04 & 36 & 286 & 198 & 108 \\
\hline 16.04 & 40 & 314 & 232 & 116 \\
\hline 17.04 & 42 & 332 & 273 & 125 \\
\hline 18.04 & 45 & 347 & 313 & 133 \\
\hline 19.04. & 47 & 360 & 361 & 141 \\
\hline 20.04 & 51 & 380 & 405 & 151 \\
\hline 21.04 & 55 & 401 & 456 & 161 \\
\hline 22.04 & 58 & 426 & 513 & 174 \\
\hline 23.04 & 60 & 454 & 555 & 187 \\
\hline 24.04 & 63 & 494 & 615 & 201 \\
\hline 25.04 & 67 & 524 & 681 & 201 \\
\hline 26.04 & 72 & 535 & 747 & 209 \\
\hline 27.04 & 75 & 562 & 794 & 220 \\
\hline 28.04 & 79 & 596 & 867 & 239 \\
\hline 29.04 & 84 & 624 & 972 & 250 \\
\hline 30.04 & 89 & 644 & 1.073 & 261 \\
\hline 01.05 & 93 & 651 & 1.169 & 272 \\
\hline 02.05 & 97 & 664 & 1.222 & 279 \\
\hline 03.05 & 99 & 678 & 1.280 & 288 \\
\hline 04.05 & 103 & 698 & 1.356 & 303 \\
\hline 05.05 & 107 & 716 & 1.451 & 316 \\
\hline 06.05 & 112 & 733 & 1.537 & 327 \\
\hline 07.05 & 116 & 755 & 1.625 & 340 \\
\hline 08.05 & 121 & 776 & 1.723 & 361 \\
\hline 09.05 & 126 & 785 & 1.827 & 376 \\
\hline 10.05 & 131 & 800 & 1.915 & 391 \\
\hline 11.05. & 135 & 811 & 2.009 & 408 \\
\hline 12.05 & 142 & 839 & 2.116 & 425 \\
\hline 13.05 & 146 & 861 & 2.212 & 439 \\
\hline 14.05 & 151 & 883 & 2.305 & 456 \\
\hline 15.05 & 156 & 907 & 2.418 & 476 \\
\hline 16.05 & 160 & 915 & 2.537 & 497 \\
\hline 17.05 & 165 & 925 & 2.631 & 514 \\
\hline 18.05 & 171 & 936 & 2.722 & 535 \\
\hline 19.05 & 175 & 948 & 2.837 & 548 \\
\hline 20.05 & 179 & 962 & 2.972 & 564 \\
\hline 21.05 & 185 & 972 & 3.099 & 579 \\
\hline 22.05 & 190 & 982 & 3.249 & 588 \\
\hline 23.05 & 194 & 993 & 3.388 & 605 \\
\hline 24.05 & 199 & 996 & 3.541 & 617 \\
\hline 25.05 & 204 & 1.007 & 3.633 & 623 \\
\hline
\end{tabular}

\begin{tabular}{|c|c|c|c|c|}
\hline $\begin{array}{c}\text { Datum } \\
26.05 .\end{array}$ & $\begin{array}{c}\text { Belarus } \\
208\end{array}$ & $\begin{array}{l}\text { Polen } \\
1.024\end{array}$ & $\begin{array}{c}\text { Russland } \\
3.807\end{array}$ & $\begin{array}{c}\text { Ukraine } \\
644\end{array}$ \\
\hline 27.05 & 214 & 1.028 & 3.968 & 658 \\
\hline 28.05 & 219 & 1.038 & 4.142 & 669 \\
\hline 29.05 & 224 & 1.051 & 4.374 & 679 \\
\hline 30.05 & 229 & 1.061 & 4.555 & 696 \\
\hline 31.05. & 235 & 1.064 & 4.693 & 708 \\
\hline 01.06. & 240 & 1.074 & 4.849 & 724 \\
\hline 02.06 & 243 & 1.092 & 5.031 & 733 \\
\hline 03.06 & 248 & 1.115 & 5.208 & 742 \\
\hline 04.06 & 253 & 1.117 & 5.376 & 755 \\
\hline 05.06 & 259 & 1.137 & 5.520 & 770 \\
\hline 06.06 & 263 & 1.153 & 5.717 & 785 \\
\hline 07.06 & 269 & 1.157 & 5.851 & 796 \\
\hline 08.06 & 276 & 1.166 & 5.963 & 805 \\
\hline 09.06 & 282 & 1.183 & 6.134 & 818 \\
\hline 10.06 & 288 & 1.206 & 6.350 & 841 \\
\hline 11.06. & 293 & 1.215 & 6.522 & 864 \\
\hline 12.06 & 298 & 1.222 & 6.705 & 880 \\
\hline 13.06 & 303 & 1.237 & 6.819 & 890 \\
\hline 14.06. & 308 & 1.247 & 6.938 & 899 \\
\hline 15.06 & 312 & 1.256 & 7.081 & 911 \\
\hline 16.06 & 318 & 1.272 & 7.274 & 922 \\
\hline 17.06 & 324 & 1.286 & 7.468 & 953 \\
\hline 18.06 & 331 & 1.316 & 7.650 & 976 \\
\hline 19.06. & 337 & 1.334 & 7.831 & 995 \\
\hline 20.06 & 343 & 1.346 & 7.992 & 1.004 \\
\hline 21.06 & 346 & 1.356 & 8.101 & 1.012 \\
\hline 22.06 & 351 & 1.359 & 8.196 & 1.022 \\
\hline 23.06 & 357 & 1.375 & 8.349 & 1.045 \\
\hline 24.06 & 362 & 1.396 & 8.503 & 1.061 \\
\hline 25.06 & 367 & 1.412 & 8.594 & 1.078 \\
\hline 26.06 & 373 & 1.429 & 8.770 & 1.097 \\
\hline 27.06 & 377 & 1.435 & 8.958 & 1.121 \\
\hline 28.06 & 383 & 1.438 & 9.060 & 1.142 \\
\hline 29.06 & 387 & 1.444 & 9.152 & 1.161 \\
\hline 30.06 & 392 & 1.463 & 9.306 & 1.173 \\
\hline 01.07. & 398 & 1.477 & 9.521 & 1.188 \\
\hline 02.07 & 405 & 1.492 & 9.668 & 1.200 \\
\hline 03.07 & 412 & 1.507 & 9.844 & 1.227 \\
\hline 04.07 & 418 & 1.512 & 10.011 & 1.243 \\
\hline 05.07 & 423 & 1.517 & 10.145 & 1.265 \\
\hline 06.07. & 429 & 1.521 & 10.280 & 1.278 \\
\hline 07.07. & 429 & 1.521 & 10.280 & 1.299 \\
\hline
\end{tabular}

Für die Zahlen vom 01.03.-11.04.2020, siehe Belarus-Analysen Nr. 48, S. 9.

Auch wenn die Zahlen alle aus einer Quelle stammen, sind sie nur begrenzt vergleichbar, da sich zwischen den Ländern der Umfang der Tests und die Erfassung von Covid-19 als Todesursache teilweise deutlich unterscheiden.

Quelle: Johns Hopkins Universität. Stand: 07.07.2020. 09:33 Uhr MESZ https://coronavirus.jhu.edu/map.html; https://github.com/CSSEGISandData/COVID-19/ blob/master/csse_covid_19_data/csse_covid_19_time_series/time_series_covid19_deaths_global.csv; Einwohnerzahlen:CIA World Factbook, https://www. cia.gov/library/publications/the-world-factbook/ 


\section{Covid-19-Chronik, 13. April - 14. Juni 2020}

\begin{tabular}{|c|c|c|}
\hline Datum & $\begin{array}{l}\text { Offiziell } \\
\text { bestätigte } \\
\text { Covid-19-Fälle/ } \\
\text { Todesfälle* }\end{array}$ & Ereignis \\
\hline 13.04 .2020 & $2919 / 29$ & $\begin{array}{l}\text { Präsident Aljaksandr Lukaschenka erklärt, niemand in Belarus sei allein an Covid-19 gestor- } \\
\text { ben - diese Menschen seien an einer Reihe chronischer Krankheiten gestorben, die sie bereits } \\
\text { hatten. Der Präsident fordert die Ärzte auf, für Covid-19 Patient_innen mit milden oder } \\
\text { keinen Symptomen eine ambulante Behandlung zu Hause und nicht für allzu lang (etwa } \\
\text { für } 7 \text { Tage) zu beantragen. }\end{array}$ \\
\hline 13.04 .2020 & $2919 / 29$ & $\begin{array}{l}\text { Präsident Aljaksandr Lukaschenka appelliert angesichts der Situation mit Covid-19 an den } \\
\text { Klerus, die Menschen nicht lange in Kirchen zu halten. Allerdings sollen Menschen nicht } \\
\text { daran gehindert werden, zu Ostern die Kirchen zu besuchen, so Lukaschenka. }\end{array}$ \\
\hline 13.04 .2020 & $2919 / 29$ & $\begin{array}{l}\text { Präsident Aljaksandr Lukaschenka wirft den russischen Medien eine voreingenommene } \\
\text { Berichterstattung über die Covid-19-Maßnahmen in Belarus vor. }\end{array}$ \\
\hline 14.04 .2020 & $3281 / 33$ & $\begin{array}{l}\text { Das Oberhaupt der Belarussischen orthodoxen Kirche, Metropolit Pawel, appelliert an die } \\
\text { Gläubigen, im Zusammenhang mit dem Ausbruch des Covid-19 zu Ostern keine Kirchen } \\
\text { zu besuchen. }\end{array}$ \\
\hline 14.04 .2020 & $3281 / 33$ & $\begin{array}{l}\text { Die belarussische Eishockeynationalmannschaft trifft die Entscheidung, das Training auf- } \\
\text { grund von Covid-19 zu beenden. }\end{array}$ \\
\hline 15.04 .2020 & $3728 / 36$ & $\begin{array}{l}\text { Der Botschafter Russlands in Belarus, Dmitrij Mesenzew, berichtet in einem Interview dem } \\
\text { belarussischen Nachrichtenportal tut.by über die humanitäre Hilfe für Belarus, die auf die } \\
\text { Anfrage der belarussischen Seite geleistet worden sei, darunter Testsysteme für Covid-19 } \\
\text { und Mund-Nase-Schutzmasken. }\end{array}$ \\
\hline 15.04 .2020 & $3728 / 36$ & $\begin{array}{l}\text { Laut einem Erlass des Gesundheitsministeriums sollen Patient_innen mit leichtem und } \\
\text { asymptomatischem Covid-19-Verlauf und leichter Lungenentzündung, die nicht mit Covid- } \\
19 \text { in Verbindung stehen, zu Hause behandelt werden. }\end{array}$ \\
\hline 16.04 .2020 & $4204 / 40$ & $\begin{array}{l}\text { Die WHO ist besorgt über die stabile oder zunehmende Anzahl neuer Covid-19-Fälle und } \\
\text { Todesfälle in Belarus, Russland, der Ukraine, der Türkei und Großbritannien. }\end{array}$ \\
\hline 16.04 .2020 & $4204 / 40$ & $\begin{array}{l}\text { Das belarussische Verteidigungsministerium antwortet auf eine Petition, in der über } 7.000 \\
\text { Belaruss_innen gefordert hatten, die für den 9. Mai geplante Militärparade in Minsk auf- } \\
\text { grund von Covid-19 abzusagen. "Die Vorbereitung und Durchführung der Parade ist ein } \\
\text { wesentlicher Bestandteil des Kampftrainings der Streitkräfte«, heißt es in der Antwort. }\end{array}$ \\
\hline 17.04 .2020 & $4779 / 42$ & $\begin{array}{l}\text { Der Prozentsatz der Covid-19-Infektionen unter dem medizinischen Personal sei in Belarus } \\
\text { recht hoch, berichtet der belarussische Gesundheitsminister Uladsimir Karanik. }\end{array}$ \\
\hline 17.04 .2020 & $4779 / 42$ & $\begin{array}{l}\text { Der Gesundheitsminister Uladsimir Karanik ruft Belarus_innen dazu auf, während der } \\
\text { kommenden Feiertage möglichst zu Hause zu bleiben. }\end{array}$ \\
\hline 17.04 .2020 & $4779 / 42$ & $\begin{array}{l}\text { Präsident Aljaksandr Lukaschenka verkündet die Notwendigkeit, ab der folgenden Woche } \\
\text { mit dem Unterrichtsprozess in den Schulen wieder zu beginnen. Die Schulferien waren bereits } \\
\text { zwei Mal um eine Woche verlängert worden. }\end{array}$ \\
\hline 17.04 .2020 & $4779 / 42$ & $\begin{array}{l}\text { Das Bildungsministerium berichtet in seinem Kanal auf „Telegram«, dass die Schulen ab } \\
\text { Montag, dem 20. April, zum analogen Unterricht zurückkehren sollen. Allerdings haben } \\
\text { Eltern das Recht, ihre Kinder nicht in die Schule zu schicken, wenn sie dies aufgrund der } \\
\text { Covid-19-Situation nicht möchten. }\end{array}$ \\
\hline 17.04 .2020 & $4779 / 42$ & $\begin{array}{l}\text { Präsident Aljaksandr Lukaschenka äußert seine Unzufriedenheit über die aus Russland kos- } \\
\text { tenfrei gelieferten Testsysteme für Covid-19. Laut den Aussagen von Lukaschenka liege die } \\
\text { Effektivität der Tests bei } 30 \text { Prozent. Zuvor hatte auch der Außenminister von Belarus, Ulad- } \\
\text { simir Makej, die Effektivität der Tests aus Russland bewertet (allerdings mit } 60 \text { Prozent). }\end{array}$ \\
\hline 18.04 .2020 & keine Daten/45 & $\begin{array}{l}\text { Belarussische Geschäftsleute nehmen eine Videobotschaft auf, in der sie den Staat während } \\
\text { der Pandemie um Hilfsmaßnahmen für die Unternehmen bitten. }\end{array}$ \\
\hline
\end{tabular}




\begin{tabular}{|c|c|c|}
\hline Datum & $\begin{array}{c}\text { Offiziell } \\
\text { bestätigte } \\
\text { Covid-19-Fälle/ } \\
\text { Todesfälle* }\end{array}$ & Ereignis \\
\hline 19.04 .2020 & keine Daten /47 & $\begin{array}{l}\text { Präsident Aljaksandr Lukaschenka besucht zu Ostern eine Kirche im Bezirk Smaljawitschy } \\
\text { und äußert sich u. a. zu Covid-19: "Wir erleben diese Viren jedes Jahr«, »Ich sehe jetzt nicht, } \\
\text { dass wir uns bei irgendetwas geirrt haben«, "Ich ging davon aus, dass Sie selbst Ihr Leben in } \\
\text { Ihren Händen halten und besser darüber verfügen, als ich oder vielleicht der Herrgott». Der } \\
\text { Präsident stellt dazu fest, dass die Sterblichkeit aufgrund einer Lungenentzündung, die sich } \\
\text { vor dem Hintergrund einer Covid-19-Infektion entwickelt, aktuell sehr gering sei. }\end{array}$ \\
\hline 21.04 .2020 & $6723 / 55$ & $\begin{array}{l}\text { Präsident Aljaksandr Lukaschenka betont die Bedeutung der Hilfe aus Europa während der } \\
\text { Pandemie - das gesamte Geld, das Belarus vom Internationalen Währungsfonds, der Welt- } \\
\text { bank und der Europäischen Bank für Wiederaufbau und Entwicklung erhält, werde in die } \\
\text { Gesundheitsversorgung fließen. }\end{array}$ \\
\hline 21.04 .2020 & $6723 / 55$ & $\begin{array}{l}\text { Eine Liste der Empfehlungen für Belarus, die nach einer Mission unabhängiger Expert_innen } \\
\text { der Weltgesundheitsorganisation (8.-11. April) in das Land erstellt wurde, wird veröffent- } \\
\text { licht. Darunter sind: Stärkung des Social Distancing, Informierung der breiten Öffentlich- } \\
\text { keit, Quarantäne für positiv auf Covid-19 getestete Menschen und ihre Kontaktpersonen, } \\
\text { sektorübergreifende Zusammenarbeit. }\end{array}$ \\
\hline 22.04 .2020 & $7281 / 58$ & $\begin{array}{l}\text { Das belarussische Gesundheitsministerium fordert die Bürger_innen auf, während des lan- } \\
\text { gen Wochenendes vom 25. bis 28. April zu Hause zu bleiben. }\end{array}$ \\
\hline 23.04 .2020 & $8022 / 60$ & $\begin{array}{l}\text { Belarus werde die Empfehlungen der Weltgesundheitsorganisation nicht von sich schieben, } \\
\text { erklärt Präsident Aljaksandr Lukaschenka, allerdings werde das Land der Situation entspre- } \\
\text { chend handeln. »In Belarus gibt es keine einzige Person, die an Covid-19 gestorben sei - alle } \\
\text { Opfer hatten eine lange Liste von Krankheiten«, so Lukaschenka. „Nach der Pandemie wird es } \\
\text { notwendig sein, sich der Frage zu zu wenden, welchen Lebensstil die Belarus_innen führen.» }\end{array}$ \\
\hline 24.04 .2020 & $8773 / 63$ & $\begin{array}{l}\text { Die stellvertretende Gesundheitsministerin Elena Bohdan erklärt, die Situation mit Covid-19 } \\
\text { lasse sich als kontrolliert charakterisieren. Durch die Maßnahmen gegen die Epidemie werde } \\
\text { ein lawinenartiger Anstieg der Inzidenz verhindert. Asymptomatische und milde Formen } \\
\text { der Krankheit werden derzeit zu Hause behandelt, informiert Bohdan. }\end{array}$ \\
\hline 24.04 .2020 & $8773 / 63$ & $\begin{array}{l}\text { Präsident Aljaksandr Lukaschenka unterzeichnet ein Dekret über die Maßnahmen zur Unter- } \\
\text { stützung von Unternehmen einzelner Wirtschaftssektoren, »die am anfälligsten für die nach- } \\
\text { teiligen Auswirkungen der gegenwärtigen epidemiologischen Situation sind«. }\end{array}$ \\
\hline 25.04 .2020 & $9590 / 67$ & $\begin{array}{l}\text { Trotz der Zunahme von Covid-19-Infektionsfällen sowie den Empfehlungen der Weltgesund- } \\
\text { heitsorganisation, Massenveranstaltungen abzusagen, findet in Belarus landesweit der aus } \\
\text { sowjetischen Zeiten übernommene »Subbotnik« (Verschönerungsaktivitäten in Städten und } \\
\text { auf dem Land) statt. Daran nehmen ca. 2,3 Mio. Menschen teil. Das entspricht knapp einem } \\
\text { Viertel der Gesamtbevölkerung und über der Hälfte der wirtschaftlich aktiven Menschen. }\end{array}$ \\
\hline 26.04 .2020 & $10463 / 72$ & Zum zweiten Mal trifft humanitäre Hilfe für belarussische Krankenhäuser aus China ein. \\
\hline 28.04 .2020 & $12208 / 79$ & $\begin{array}{l}\text { Das belarussische Gesundheitsministerium entwirft ein Merkblatt für Patient_innen mit } \\
\text { asymptomatischem oder mildem Ablauf von Covid-19. Nur Patient_innen unter } 55 \text { Jahre } \\
\text { und ohne chronische Krankheiten, die den Verlauf der Covid-19 Infektion verschlimmern } \\
\text { können, dürfen nach einer Entscheidung vom Arzt in Isolation zu Hause bleiben. }\end{array}$ \\
\hline 28.04 .2020 & $12208 / 79$ & $\begin{array}{l}\text { Die residierende Koordinatorin der Vereinten Nationen in Belarus, Joanne Kazana-Wis- } \\
\text { niowiecki, ruft die Belarus_innen dazu auf, zu Hause zu bleiben. „Wir beobachten derzeit } \\
\text { die Entwicklung eines Ausbruchs der Covid-19-Infektion in Belarus, der durch eine stetige } \\
\text { und sich ausbreitende lokale Übertragung gekennzeichnet ist«, so Kazana-Wisniowiecki. }\end{array}$ \\
\hline 28.04.2020 & $12208 / 79$ & $\begin{array}{l}\text { Ein Bericht der WHO-Mission nach Belarus (8.-11. April) wird veröffentlicht. Die Situa- } \\
\text { tion in Belarus sei laut dem Bericht besorgniserregend - Belarus habe ein neues Stadium } \\
\text { der Pandemie (community transmission) erreicht. Es wird u. a. empfohlen, Massenveranstal- } \\
\text { tungen abzusagen, die Arbeit zu Hause einzuführen und ein breites Publikum regelmäßig } \\
\text { und umfassend über die Entwicklung der Situation mit Covid-19 in Belarus zu informieren. }\end{array}$ \\
\hline 29.04 .2020 & $13181 / 84$ & $\begin{array}{l}\text { Voraussichtlich werden die Auswirkungen von Covid-19 auf Belarus sehr groß sein, erklärt } \\
\text { Katarina Maternová, die stellvertretende Generaldirektorin der Abteilung für europäische } \\
\text { Nachbarschaftspolitik und Erweiterungsverhandlungen der Europäischen Kommission. }\end{array}$ \\
\hline
\end{tabular}




\begin{tabular}{|c|c|c|}
\hline Datum & $\begin{array}{c}\text { Offiziell } \\
\text { bestätigte } \\
\text { Covid-19-Fälle/ } \\
\text { Todesfälle* }\end{array}$ & Ereignis \\
\hline 30.04 .2020 & $14027 / 89$ & $\begin{array}{l}\text { Josep Borrell, der hohe Vertreter der Europäischen Union für Außen- und Sicherheitspoli- } \\
\text { tik, erklärt, die EU erwarte, dass Belarus den Empfehlungen der WHO zur Bekämpfung } \\
\text { des Covid-19 im Gegenzug gegen eine geplante finanzielle Unterstützung seitens der EU } \\
\text { (60 Mio. Euro) folgt. }\end{array}$ \\
\hline 02.05 .2020 & $15828 / 97$ & $\begin{array}{l}\text { Fast zwei Drittel der Krankenhausbetten für Patient_innen mit Covid-19 und Lungenent- } \\
\text { zündung seien in Belarus besetzt, so der staatliche Fernsehsender »Belarus-1«. }\end{array}$ \\
\hline 02.05 .2020 & $15828 / 97$ & $\begin{array}{l}\text { Die Covid-19-Maßnahmen in Belarus seien der aktuellen Situation angemessen, so die Spre- } \\
\text { cherin des Republikrates, Natallja Katschanawa. Die Hauptsache sei hier die Verfügbarkeit } \\
\text { von medizinischen Geräten, Medikamenten, behandelnden Ärzten und Plätzen in den Kran- } \\
\text { kenhäusern; all dies sei vorhanden, meint Katschanawa. }\end{array}$ \\
\hline 03.05 .2020 & $16705 / 99$ & $\begin{array}{l}\text { Nur ca. } 10 \text { Prozent der verfügbaren Beatmungsgeräte (über 200) seien in Belarus im Ein- } \\
\text { satz, erklärt Präsident Lukaschenka. Zudem werde innerhalb von } 4 \text { Monaten die Gesamt- } \\
\text { mortalität im Land um } 1,5 \% \text { sinken, so Lukaschenka. }\end{array}$ \\
\hline 04.05 .2020 & $17489 / 103$ & $\begin{array}{l}\text { Die Situation mit Covid-19 und den Lungenentzündungen in Wizebsk habe sich stabilisiert, } \\
\text { berichtet das Gesundheitsministerium. Die Region Wizebsk liegt in Belarus in Bezug auf die } \\
\text { Anzahl der festgestellten Fälle von Covid-19-Infektionen an zweiter Stelle. }\end{array}$ \\
\hline 04.05 .2020 & $17489 / 103$ & $\begin{array}{l}\text { Eine Petition mit über } 5.000 \text { Unterschriften für einen Rücktritt des belarussischen Bil- } \\
\text { dungsministers Ihar Karpenka wird an die Präsidialadministration übergeben. Als Grund } \\
\text { wird genannt, dass er die Herausforderungen der Covid-19-Pandemie nicht habe bewälti- } \\
\text { gen können. }\end{array}$ \\
\hline 06.05 .2020 & $19255 / 112$ & $\begin{array}{l}\text { In Russland hoffe man, dass Unterschiede in der Taktik zur Bekämpfung des Covid-19 in } \\
\text { Belarus und Russland nicht zu einem explosionsartigen Anstieg der Zahl der Infizierten füh- } \\
\text { ren werden, erklärt Dmitrij Peskow, Pressesprecher des Präsidenten Russlands. }\end{array}$ \\
\hline 06.05 .2020 & $19255 / 112$ & $\begin{array}{l}\text { Das belarussische Außenministerium widerruft die Akkreditierung eines Journalisten des } \\
\text { russischen Fernsehsenders »Erster Kanal«, nachdem dieser eine kritische Reportage über die } \\
\text { Situation mit Covid-19 in Belarus gemacht hat. }\end{array}$ \\
\hline 05.05 .2020 & $18350 / 107$ & $\begin{array}{l}\text { Die belarussische Regierung modifiziert die Isolierungsregel für positiv auf Covid-19 getes- } \\
\text { tete Bürger_innen. Sie müssen u. a. die Ärzte über alle ihrer Kontakte und Aufenthaltsorte } \\
\text { als mögliche Infektionsquellen informieren; diese Menschen sowie ihre Kontakte ersten Gra- } \\
\text { des müssen einer medizinischen Untersuchung unterzogen werden; die Aufenthaltsdauer der } \\
\text { Bürger_innen mit Covid-19 in Isolation darf von Gesundheitsbehörden und -einrichtungen } \\
\text { nicht nur verlängert, sondern auch verkürzt werden. }\end{array}$ \\
\hline 08.05 .2020 & $21101 / 121$ & $\begin{array}{l}\text { Der belarussische Gesundheitsminister Uladsimir Karanik schließt die Möglichkeit einer } \\
\text { zweiten Inzidenzwelle des Covid-19 im Herbst und Winter nicht aus. }\end{array}$ \\
\hline 09.05 .2020 & $22052 / 126$ & $\begin{array}{l}\text { In Minsk findet eine Militärparade zum 75. Jahrestag des Sieges im Zweiten Weltkrieg statt. } \\
\text { "Wir konnten es einfach nicht anders machen, wir hatten keine andere Wahl«, erklärt Prä-- } \\
\text { sident Aljaksandr Lukaschenka und betont die Bedeutung dieses Datums für die belarussi- } \\
\text { sche Geschichte. Aufgrund der Covid-19-Pandemie nehmen an der Parade allerdings deut- } \\
\text { lich weniger Menschen teil als normalerweise. Belarus und Turkmenistan sind die einzigen } \\
\text { ehemaligen Sowjetrepubliken, die die Feierlichkeiten am 9. Mai im Jahr } 2020 \text { nicht abge- } \\
\text { sagt haben. }\end{array}$ \\
\hline 09.05 .2020 & $22052 / 126$ & $\begin{array}{l}\text { Die belarussische Regierung hebt das Exportverbot für Gaze, Bandagen, Watte und Masken } \\
\text { auf. Das Verbot war aufgrund der Situation mit Covid-19 am 17. März eingeführt worden. }\end{array}$ \\
\hline 12.05 .2020 & $6974 / 142$ & $\begin{array}{l}\text { Präsident Aljaksandr Lukaschenka ist überzeugt, dass die belarussische Strategie gegen } \\
\text { Covid-19 das von ihm gewünschte Ergebnis bringt. Er glaubt zudem, dass Staaten im Wes- } \\
\text { ten die belarussischen Methoden bereits ebenfalls nutzten: es gebe langsame Lockerungen, } \\
\text { die Wirtschaft beginne wieder zu funktionieren. }\end{array}$ \\
\hline 13.05 .2020 & $25825 / 146$ & $\begin{array}{l}\text { Nichtstaatliche Medien berichten darüber, dass Belarus laut »ourworldindata.org« unter den } \\
\text { Ländern der ehemaligen UdSSR sowie unter seinen Nachbarländern die höchste Anzahl der } \\
\text { bestätigten Covid-19-Fälle pro } 1 \text { Mio. Menschen hat. }\end{array}$ \\
\hline
\end{tabular}




\begin{tabular}{|c|c|c|}
\hline Datum & $\begin{array}{l}\text { Offiziell } \\
\text { bestätigte } \\
\text { Covid-19-Fälle/ } \\
\text { Todesfälle* }\end{array}$ & Ereignis \\
\hline 13.05 .2020 & $25825 / 146$ & Zum dritten Mal trifft humanitäre Hilfe für belarussische Krankenhäuser aus China ein. \\
\hline 14.05 .2020 & $25825 / 146$ & $\begin{array}{l}\text { Laut dem belarussischen Gesundheitsministerium habe Belarus das Covid-19-Inzidenzpla- } \\
\text { teau erreicht. Elena Bohdan, stellvertretende Gesundheitsministerin, betont, dass die bela- } \\
\text { russische Bevölkerung so breit wie möglich getestet wird, und ca. } 64 \text { Prozent der gesamten } \\
\text { Identifikationen der Infizierten über Kontaktpersonen erfolgen. }\end{array}$ \\
\hline 15.05 .2020 & $27730 / 156$ & $\begin{array}{l}\text { Nichtstaatliche Medien berichten darüber, dass das belarussische Gesundheitsministerium } \\
\text { seit fast drei Wochen keine Streams und Briefings zu Covid-19 organisiert hat. }\end{array}$ \\
\hline 17.05 .2020 & $29650 / 165$ & $\begin{array}{l}\text { Mehr als } 100 \text { Patient_innen mit Covid-19 erhielten in Belarus eine Plasmabehandlung, } \\
\text { berichtet Fjodar Karpenka, Direktor des Republikanischen Wissenschaftlichen und Prak- } \\
\text { tischen Zentrums für Transfusion und medizinische Biotechnologie. }\end{array}$ \\
\hline 19.05 .2020 & $31508 / 175$ & $\begin{array}{l}\text { Belarussische Ärzte schreiben einen gemeinsamen Appell an die Präsidialverwaltung wegen } \\
\text { der nicht ausgezahlten Zuschläge für ihre Arbeit mit Covid-19 Patient_innen. }\end{array}$ \\
\hline 19.05 .2020 & $31508 / 175$ & $\begin{array}{l}\text { der EU-Kommissar für Nachbarschaft und Erweiterung, Olivér Várhelyi erklärt, Belarus } \\
\text { verfolge während der Coronavirus-Pandemie einen völlig anderen (kooperativen) Ansatz in } \\
\text { Bezug auf die Beziehungen zur EU als zuvor. }\end{array}$ \\
\hline 21.05 .2020 & $33371 / 185$ & $\begin{array}{l}\text { Präsident Aljaksandr Lukaschenka weist darauf hin, dass die Covid-19-Sterbequote in Bela- } \\
\text { rus eine der niedrigsten in der Welt sei. }\end{array}$ \\
\hline 26.05 .2020 & $38059 / 208$ & $\begin{array}{l}\text { Die Krankenhäuser und Gesundheitseinrichtungen in Minsk kehren zur planmäßigen } \\
\text { Arbeitsweise zurück, berichtet das Gesundheitsministerium. }\end{array}$ \\
\hline 28.05.2020 & $39858 / 219$ & $\begin{array}{l}\text { Zehn Abgeordnete des Europäischen Parlaments wenden sich an das belarussische Volk, um } \\
\text { ihre Solidarität während der Pandemie zu bekunden. }\end{array}$ \\
\hline 28.05.2020 & $39858 / 219$ & $\begin{array}{l}\text { Belarus gehört laut der Weltgesundheitsorganisation zu den fünf europäischen Ländern, in } \\
\text { denen über die letzten } 14 \text { Tage hinweg die höchste kumulierte Anzahl bestätigter Covid-19- } \\
\text { Neuinfizierter verzeichnet wurde. }\end{array}$ \\
\hline 29.05 .2020 & $40764 / 224$ & $\begin{array}{l}\text { Präsident Aljaksandr Lukaschenka stellt fest, dass die getroffene Entscheidung, die Pro- } \\
\text { duktion im Land während der Pandemie nicht einzustellen richtig war. »Im reichen Westen } \\
\text { gibt es bereits wilde Arbeitslosigkeit [...] Gott sei Dank, dass wir dies vermieden haben«, } \\
\text { sagte Lukaschenka. }\end{array}$ \\
\hline 01.06 .2020 & $43403 / 240$ & $\begin{array}{l}\text { Der belarussische Gesundheitsminister Uladsimir Karanik und der Leiter der Repräsentanz } \\
\text { der Weltbank in Belarus, Alex Kremer, unterzeichnen online Dokumente über finanzielle } \\
\text { Hilfe für Belarus in Zusammenhang mit Covid-19 in Höhe von } 90 \text { Mio. Euro. }\end{array}$ \\
\hline 05.06 .2020 & $46868 / 259$ & $\begin{array}{l}\text { Fast die Hälfte der Bevölkerung von Belarus habe den Höhepunkt der Covid-19-Epidemie } \\
\text { überschritten, inklusive Minsk und Wizebsk Regionen (40-45 Prozent der belarussischen } \\
\text { Bevölkerung), so die stellvertretende Gesundheitsministerin Elena Bohdan. }\end{array}$ \\
\hline 05.06 .2020 & $46868 / 259$ & Humanitäre Hilfe aus Polen kommt in Belarus an. \\
\hline 11.06 .2020 & $51816 / 293$ & $\begin{array}{l}\text { Gesundheitsminister Uladsimir Karanik erklärt, dass man in Belarus das Labornetzwerk } \\
\text { verbessert, ausgebaut und erweitert habe, während die sanitär-epidemiologischen Dienste } \\
\text { weltweit reduziert worden seien. Dies habe dazu beigetragen, dass die Covid-19-Todesrate } \\
\text { in Belarus eine der niedrigsten in der Welt sei (unter 1\%), so Karanik. }\end{array}$ \\
\hline 12.06 .2020 & $52520 / 298$ & $\begin{array}{l}\text { Batyr Berdyklychev, Leiter des WHO-Büros in Belarus, betont, dass Belarus sich immer } \\
\text { noch im Stadium der lokalen Übertragung (community transmission) des Covid-19 befindet, } \\
\text { was eine ziemlich ernste Situation darstelle. }\end{array}$ \\
\hline
\end{tabular}

${ }^{*}$ Quelle: Johns Hopkins Universität und Gesundheitsministerium von Belarus, Stand: 14.06.2020

Chronik zusammengestellt auf der Grundlage von Meldungen der Nachrichtenportale naviny.by, tut.by und weiteren sowie des Gesundheitsministeriums von Belarus. 


\section{April - 14. Juni 2020}

\begin{tabular}{|c|c|}
\hline 14.04 .2020 & $\begin{array}{l}\text { Präsident Aljaksandr Lukaschenka fordert den Präsidenten der Russischen Föderation, Wladimir Putin, wäh- } \\
\text { rend eines Arbeitstreffens der Mitglieder des Obersten Eurasischen Wirtschaftsrates, das per Videokonferenz } \\
\text { stattfindet, dazu auf, die Frage der Erdgaspreise für Belarus unverzüglich zu erörtern. }\end{array}$ \\
\hline 14.04 .2020 & $\begin{array}{l}\text { Im Bericht des Internationalen Währungsfonds wird eine Prognose veröffentlicht, der zufolge das belarussi- } \\
\text { sche Bruttoinlandsprodukt } 2020 \text { um } 6 \text { Prozent sinken wird. }\end{array}$ \\
\hline 16.04 .2020 & "Amnesty International« bewertet die Menschenrechtssituation in Belarus im Jahr 2019 als kritisch. \\
\hline 06.05 .2020 & $\begin{array}{l}\text { Litauen fordert Belarus dazu auf, die Inbetriebnahme des belarussischen Atomkraftwerks bei Astrawez aus } \\
\text { Sicherheitsgründen zu verschieben und den Kernbrennstoff erst dann zu verladen, wenn alle Empfehlungen } \\
\text { internationaler Expert_innen umgesetzt sind. }\end{array}$ \\
\hline 06.05 .2020 & $\begin{array}{l}\text { Der bekannte belarussische Blogger Sjarhej Zichanouski („YouTube«-Kanal "Land für das Leben« mit über } \\
180.000 \text { Abonnent_innen) wird in der Nähe von Mahiljou festgenommen. Seit über einem Monat war Zicha- } \\
\text { nouski durch das Land gereist und hatte sich mit Kanalabonnent_innen getroffen, um die Probleme unter- } \\
\text { schiedlicher Menschen aufzugreifen und Reportagen zu machen. }\end{array}$ \\
\hline $\begin{array}{l}06 .- \\
09.05 .2020\end{array}$ & $\begin{array}{l}\text { In Minsk, Homel und weiteren belarussischen Städten werden nach Angaben von Menschenrechtler_innen ca. } \\
100 \text { Anhänger_innen des Bloggers Sjarhej Zichanouski festgenommen. }\end{array}$ \\
\hline 08.05 .2020 & Die Zentrale Wahlkommission schlägt den 9. August als Datum für die Präsidentschaftswahlen vor. \\
\hline 12.05.2020 & Die Europäische Union verurteilt die Festnahmen von Demonstrant_innen, zu denen es in ganz Belarus. \\
\hline 13.05 .2020 & $\begin{array}{l}\text { Harlem Désir, Beauftragter für die Freiheit der Medien der OSZE, verurteilt die Verhaftung von Journalist_ } \\
\text { innen für ihre angebliche Teilnahme an nicht genehmigten Kundgebungen. }\end{array}$ \\
\hline 13.05 & $\begin{array}{l}\text { Die Menschenrechtsorganisation »Reporter ohne Grenzen« gibt eine Erklärung heraus, in der die Freilassung } \\
\text { der in Belarus inhaftierten Journalist_innen gefordert wird. }\end{array}$ \\
\hline 15.05 & $\begin{array}{l}\text { Die Zentrale Wahlkommission lehnt für eine Reihe der »Protestkandidaten« die Registrierung der Initiativ- } \\
\text { gruppen zur Nominierung eines Präsidentschaftskandidaten ab. Darunter sind Sjarhej Zichanouski, der am } \\
\text { 6. Mai festgenommen wurde, sowie der ehemalige Präsidentschaftskandidat Mikalaj Statkewitsch, der nach } \\
\text { den Wahlen-2010 verhaftet und von Menschenrechler_innen als politischer Gefangener anerkannt worden } \\
\text { war. Zichanouskis Ehefrau, Swjatlana Zichanouskaja, entscheidet spontan, eine eigene Initiativgruppe regis- } \\
\text { trieren zu lassen, was ihr auch gelingt. Insgesamt reichten } 55 \text { Bürger_innen bei der Zentralen Wahlkommis- } \\
\text { sion Anträge auf die Registrierung einer Initiativgruppe ein. }\end{array}$ \\
\hline 18.05 & $\begin{array}{l}\text { Der Prozess der Präsidentschaftswahlen in Belarus beginnt vor dem Hintergrund der Covid-19-Epidemie und } \\
\text { der sich verschlechternden Menschenrechtssituation in Belarus, erklärt die Kampagne »Menschenrechtsver- } \\
\text { teidiger für freie Wahlen«. }\end{array}$ \\
\hline 19.05 .2020 & Die Europäische Union fordert die sofortige Freilassung der in Belarus festgenommenen Journalist_innen. \\
\hline 20.05 .2020 & $\begin{array}{l}\text { Fünfzehn Initiativgruppen für eine Nominierung von Präsidentschaftskandidat_innen werden registriert, } \\
\text { darunter für den ehemaligen Direktor der »Belgazprombank«, Wiktar Babaryka, und den ehemaligen Direk- } \\
\text { tor des High-Tech-Parks, Waleryj Zepkala. }\end{array}$ \\
\hline 25.05 . & $\begin{array}{l}\text { Im Vergleich zu den Wahlen von } 2015 \text { hat sich Menschenrechtlern zufolge der Anteil von Oppositionellen in } \\
\text { den Territorialen Wahlkommissionen auf ein Fünfzehntel verringert. }\end{array}$ \\
\hline 26.05 .2020 & $\begin{array}{l}\text { Der Vorsitzende der Liberaldemokratischen Partei (die von Expert_innen als »systemische Opposition«betrach- } \\
\text { tet wird), Aleh Hajdukewitsch, zieht sich von den Wahlen zurück, weil seine »politischen Ambitionen der Situa- } \\
\text { tion im Land unterlegen sind«. Expert_innen interpretieren den Schritt als Versuch des Regimes, die Stim- } \\
\text { men für Aljaksandr Lukaschenka in dem angeblich schwierigen politischen Kampf nicht abwandern zu lassen. }\end{array}$ \\
\hline 27.05 .2020 & $\begin{array}{l}\text { Die internationale Organisation »Human Rights Watch« erklärt, durch die Verhaftung von Teilnehmern an } \\
\text { friedlichen Versammlungen inmitten einer Pandemie erzeugten die belarussischen Behörden eine Gefahr für } \\
\text { das Leben der Bürger_innen. }\end{array}$ \\
\hline 28.05 .2020 & $\begin{array}{l}\text { Belarussische Medien berichten über landesweit beispiellos lange Schlangen von Menschen, die trotzt der } \\
\text { Covid-19-Pandemie bereit sind, lange zu warten, um mit ihrer Unterschrift alternative Präsidentschaftskan- } \\
\text { didat_innen unterstützen zu können. Insgesamt seien an dem Tag über } 10.000 \text { Unterschriften für alternative } \\
\text { Kandidat_innen gesammelt worden. }\end{array}$ \\
\hline
\end{tabular}




\begin{tabular}{|c|c|}
\hline 29.05 .2020 & $\begin{array}{l}\text { Das Europäische Parlament erklärt seine Besorgnis angesichts der Repressionen in Belarus am Vorabend der } \\
\text { Präsidentschaftswahlen. Dies geht aus einer gemeinsamen Erklärung des Vorsitzenden der Delegation des Euro- } \\
\text { päischen Parlaments für die Beziehungen zu Belarus, Robert Biedroń, und von Petras Auštrevičius, dem Stän- } \\
\text { digen Berichterstatter zu Belarus, hervor. }\end{array}$ \\
\hline 29.05 .2020 & $\begin{array}{l}\text { Präsident Lukaschenka erklärt: „Unsere Verfassung ist nicht für eine Frau. Und unsere Gesellschaft ist nicht } \\
\text { reif, für eine Frau zu stimmen«. Seine Worte verursachen eine harsche Kritik in den belarussischen Medien } \\
\text { und sozialen Medien. }\end{array}$ \\
\hline 29.05 .2020 & $\begin{array}{l}\text { Der Blogger Sjarhej Zichanouski wird während einer Wahlveranstaltung in Hrodna zum zweiten Mal festge- } \\
\text { nommen. Expert_innen, nicht-staatliche Medien sowie seine Frau, Swjatlana Zihanouskaja, die an Stelle von } \\
\text { Zichanouski kandidieren will, berichten über eine offensichtliche Provokation, die zu Auseinandersetzung mit } \\
\text { der Polizei geführt habe. }\end{array}$ \\
\hline 31.05 .2020 & $\begin{array}{l}\text { Belarussische Medien berichten erneut über beispiellos lange Schlangen von Menschen in Minsk und Hrodna, } \\
\text { die für alternative Präsidentschaftskandidat_innen unterschreiben möchten. Swjatlana Zichanouskaja verzeich- } \\
\text { net die längsten Schlangen: Die Menschen seien noch aktiver geworden, nachdem ihr Mann und "YouTube«- } \\
\text { Blogger, Sjarhej Zihcanouski, am 29. Mai festgenommen wurde. Die Menschen erklären ihre Unterschriften } \\
\text { für Zichanouskaja als »Proteststimmen«. Ca. } 2.000 \text { Menschen nehmen in Minsk an einer spontanen Kundge- } \\
\text { bung mit der Forderung nach einem Rücktritt von Lukaschenka teil. }\end{array}$ \\
\hline 01.06 .2020 & $\begin{array}{l}\text { Menschenrechtler verzeichnen landesweit eine Vielzahl von Festnahmen von Unterschriftensammlern: vom } \\
\text { 6. bis 31. Mai seine landesweit } 195 \text { Personen festgenommen worden, die an politischen und Umweltprotesten } \\
\text { teilnahmen oder diese beobachteten. }\end{array}$ \\
\hline 01.06 .2020 & $\begin{array}{l}\text { Wiktar Babaryka, Anwärter auf das Amt des Präsidenten, reicht bei der Zentralen Wahlkommission eine } \\
\text { Beschwerde gegen Präsident Aljaksandr Lukaschenka wegen Verstoßes gegen das Wahlgesetz ein. Babaryka } \\
\text { verweist auf den Einsatz administrative Ressourcen bei der Sammlung von Unterschriften für die Nominie- } \\
\text { rung des amtierenden Präsidenten Lukaschenka als Kandidaten hin. Babaryka verweist auch im Zusammen- } \\
\text { hang mit dem Wahlkampf, der nicht vor der Registrierung als Präsidentschaftskandidat_in stattfinden darf, } \\
\text { auf Verstöße gegen das Wahlgesetz. }\end{array}$ \\
\hline 02.06 .2020 & $\begin{array}{l}\text { Die Europäische Union fordert die belarussischen Behörden zur sofortigen Freilassung der festgenommenen } \\
\text { Aktivist_innen in Belarus auf. }\end{array}$ \\
\hline 02.06 .2020 & $\begin{array}{l}\text { In einer gemeinsamen Erklärung des Leiters der Delegation des Europäischen Parlaments für die Beziehun- } \\
\text { gen zu Belarus, Robert Biedroń, und des Ständigen Berichterstatters des Europäischen Parlaments zu Bela- } \\
\text { rus, Petras Auštrevičius, wird die Festnahme von Aktivist_innen in Belarus verurteilt und vor der Möglich- } \\
\text { keit neuer EU-Sanktionen gewarnt. }\end{array}$ \\
\hline 03.06 .2020 & $\begin{array}{l}\text { In einer gemeinsamen Erklärung der Vertretung der Europäischen Union sowie der britischen und der US-ameri- } \\
\text { kanischen Botschaft in Belarus heißt es, die belarussischen Behörden sollten die notwendigen Maßnahmen ergrei- } \\
\text { fen, um »sichere, friedliche, freie und faire Wahlen durchzuführen und die Grundfreiheiten zu gewährleisten". }\end{array}$ \\
\hline 03.06 .2020 & $\begin{array}{l}\text { Die Zentrale Wahlkommission sieht keinen Grund, Aljaksandr Lukaschenka wegen seiner diskriminierenden } \\
\text { Aussagen über belarussische Frauen zu verwarnen. }\end{array}$ \\
\hline 03.06 .2020 & $\begin{array}{l}\text { Bei der dritten Durchsuchung im Haus des »YouTube«-Bloggers Sjarhej Zichanouski wurden laut den staatli- } \\
\text { chen Medien } 900.000 \text { US-Dollar hinter einem Sofa gefunden. }\end{array}$ \\
\hline 03.06 .2020 & Aljaksandr Lukaschenka entlässt die Regierung. \\
\hline 04.06 .2020 & $\begin{array}{l}\text { Raman Haloutschenka wird zum neuen belarussischen Ministerpräsidenten ernannt. Zuvor war er Vorsitzen- } \\
\text { der des Militärisch-industriellen Staatskomitees. }\end{array}$ \\
\hline 04.06 .2020 & $\begin{array}{l}\text { Die Zentrale Wahlkommission erklärt, dass es bei der Unterschriftensammlung für Aljaksandr Lukaschenka } \\
\text { keine Verstöße gegeben habe. }\end{array}$ \\
\hline 04.06 .2020 & $\begin{array}{l}\text { Aljaksandr Lukaschenka äußert sich negativ über alternative potenzielle Präsidentschaftskandidat_innen und } \\
\text { sagt unter anderem Folgendes: "Sie werden das Land nicht bekommen«, „Wir werden dieses Land keinem über- } \\
\text { geben«, »Mein ganzes Leben ist in diesem Land". }\end{array}$ \\
\hline 07.06 .2020 & $\begin{array}{l}\text { Der neue Informationsminister von Belarus, Ihar Luzki, erklärt, die Strategie des Informationsministeriums } \\
\text { werde darin bestehen, die Tätigkeit der Medien zu korrigieren, um sicherzustellen, dass [den Menschen] eine } \\
\text { klare staatliche Politik vermittelt wird, und die Bevölkerung von Informationen fernzuhalten, die für den Staat } \\
\text { schädlich sind. }\end{array}$ \\
\hline 10.06.2020 & $\begin{array}{l}\text { Präsident Lukaschenka erklärt: "Zur rechten Zeit und am richtigen Ort werden wir alle zur Besinnung brin- } \\
\text { gen. Es wird keinen Umstürz im Land geben. Umso weniger einen »Maidan«. }\end{array}$ \\
\hline
\end{tabular}




\begin{tabular}{|c|c|}
\hline 03.06 .2020 & $\begin{array}{l}\text { Die potenzielle Präsidentschaftskandidatin Swjatlana Zichanouskaja, die Ehefrau des »YouTube«-Bloggers Sjar- } \\
\text { hej Zichanouski (»Staat für das Leben«), ruft ihre Initiativgruppen dazu auf, wegen der regelmäßigen Festnah- } \\
\text { men von Mitgliedern ihrer Initiativgruppen sowie Aktionen von Provokateuren in den kommenden drei Tagen } \\
\text { keine Stände für Unterschriftensammlungen zu organisieren. }\end{array}$ \\
\hline 11.06 .2020 & $\begin{array}{l}\text { Der litauische Regierungschef Saulius Skvernelis fordert Lettland und Estland auf, auf den Kauf von Strom } \\
\text { aus dem belarussischen Kernkraftwerk zu verzichten. }\end{array}$ \\
\hline 11.06 .2020 & $\begin{array}{l}\text { Die »Belgazprombank« wird von den Behörden durchgesucht. Wiktar Babaryka, ehemaliger Direktor der Bank } \\
\text { und potenzieller Präsidentschaftskandidat, erklärt, dass der Sinn dieser Aktionen darin bestehe, seitens des } \\
\text { Staates Druck auf ihn auszuüben. }\end{array}$ \\
\hline 11.06 .2020 & $\begin{array}{l}\text { Die russischen Aktionäre der "Belgazprombank» - "Gazprom» und »Bank GPB« (»Gazprombank») - bekun- } \\
\text { den ihre uneingeschränkte Unterstützung für ihre belarussische Tochterbank und ihre Bereitschaft, mit der } \\
\text { belarussischen Nationalbank zu kommunizieren und zur Lösung der Situation beizutragen. }\end{array}$ \\
\hline 11.06 .2020 & $\begin{array}{l}\text { Belarussische Menschenrechtler fordern die Regierung auf, Bürger_innen, die sich an den Wahlen beteiligen, } \\
\text { nicht einzuschüchtern. }\end{array}$ \\
\hline 11.06 .2020 & $\begin{array}{l}\text { Die "Belgazprombank« kündigt einseitig den Vertrag über die Abwicklung der Operationen der Crowdfun- } \\
\text { ding-Plattform "MolaMola». "MolaMola« ist eine Spendenplattform, die über die Crowdfunding-Plattform } \\
\text { Ulej.by gestartet wurde - sie wurde von Eduard Babaryka, dem Sohn von Wiktar Babaryka, initiiert. Über } \\
\text { "MolaMola« wurde auch Fundraising im Rahmen der Bekämpfung mit der Covid-19 Pandemie unternommen. }\end{array}$ \\
\hline 12.06 .2020 & $\begin{array}{l}\text { "Gazprombank« und »Gazprom« erklären die Ernennung einer neuen Geschäftsführung der »Belgazprombank» } \\
\text { als rechtswidrig7. »[...] der Vorstand der Nationalbank der Republik Belarus hat durch rechtswidrige Hand- } \\
\text { lungen einen geschäftsführenden Vorstandsvorsitzenden [...] der »Belgazprombank« benannt. Diese Ernen- } \\
\text { nungen gingen mit der Festnahme autorisierter Vorstandsmitglieder der »Belgazprombank« einher«, heißt es } \\
\text { in der Erklärung. }\end{array}$ \\
\hline 14.06 .2020 & $\begin{array}{l}\text { Der ehemalige Direktor der "Belgazprombank« und potenzielle Präsidentschaftskandidat Wiktar Babaryka } \\
\text { bezeichnet das Vorgehen des Staates und das Strafverfahren gegen einen Angestellten der "Belgazprombank» } \\
\text { als "feindliche Übernahme durch den Staat«. }\end{array}$ \\
\hline
\end{tabular}

Zusammengestellt auf der Grundlage von Meldungen der Nachrichten-Agenturen BelaPAN und BelTa sowie des Nachrichtenportals naviny.by.

Sie können die gesamte Chronik ab dem 14.03.2011 auch auf http://www.laender-analysen.de/belarus/ unter dem Link »Chronik«lesen.

\author{
Herausgeber: \\ Forschungsstelle Osteuropa an der Universität Bremen \\ Deutsche Gesellschaft für Osteuropakunde e.V. \\ Deutsches Polen-Institut \\ Leibniz-Institut für Agrarentwicklung in Transformationsökonomien \\ Leibniz-Institut für Ost- und Südosteuropaforschung \\ Zentrum für Osteuropa- und internationale Studien (ZOiS) gGmbH \\ Redaktion: \\ Olga Dryndova (verantwortlich) \\ Sprachredaktion: Hartmut Schröder \\ Satz: Matthias Neumann \\ Wissenschaftlicher Beirat: \\ Prof. Dr. Margarita Balmaceda, Seton Hall University / Harvard University \\ Prof. Dr. Heiko Pleines, Forschungsstelle Osteuropa an der Universität Bremen \\ Dr. Astrid Sahm, IBB Dortmund
}

Die Meinungen, die in den Belarus-Analysen geäußert werden, geben ausschließlich die Auffassung der Autoren wieder

Abdruck und sonstige publizistische Nutzung sind nach Rücksprache mit der Redaktion gestattet.

Belarus-Analysen-Layout: Cengiz Kibaroglu, Matthias Neumann und Michael Clemens

Alle Ausgaben der Belarus-Analysen sind mit Themen- und Autorenindex archiviert unter www.laender-analysen.de ISSN 2192-1350 @ 2020 by Forschungsstelle Osteuropa an der Universität Bremen

Forschungsstelle Osteuropa • Länder-Analysen • Klagenfurter Str. • • 28359 Bremen • Telefon: +49 421-218-69600 • Telefax: + 49 421-218-69607 e-mail: laender-analysen@uni-bremen.de•Internet-Adresse: http://www.laender-analysen.de/belarus 


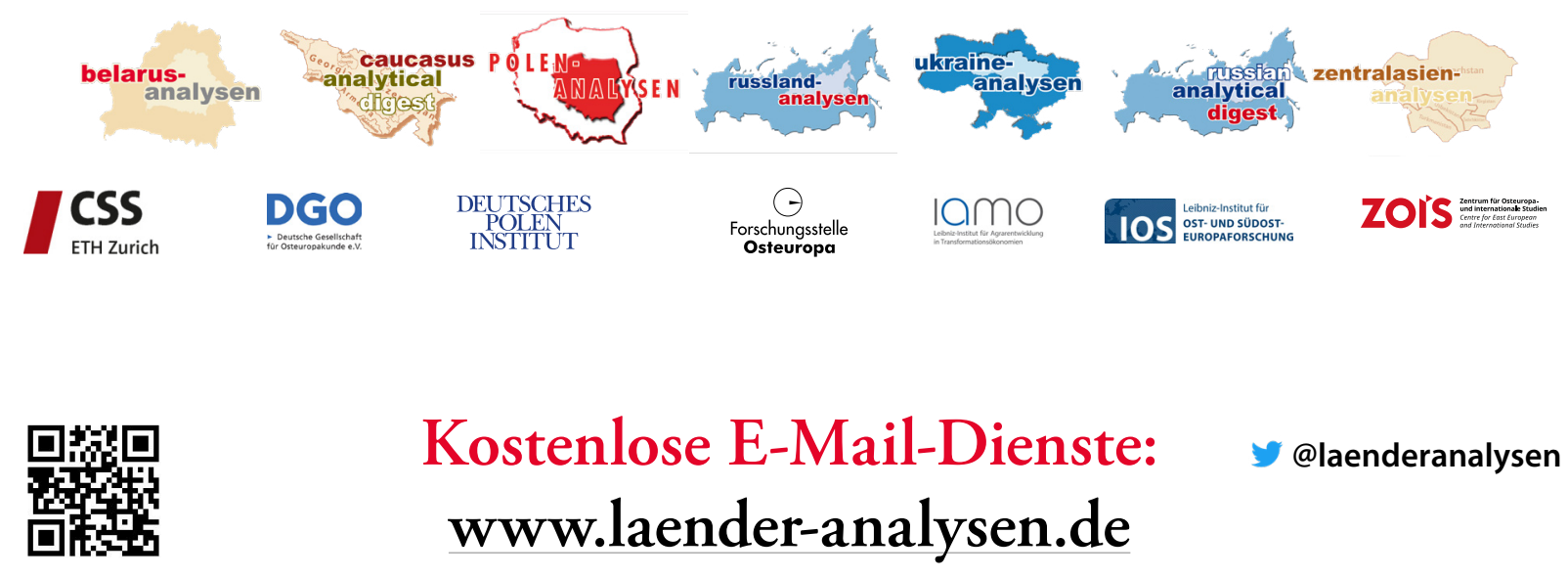

Die Länder-Analysen bieten regelmäßig im kostenlosen Abonnement kompetente Einschätzungen aktueller politischer, wirtschaftlicher, sozialer und kultureller Entwicklungen in Ostmitteleuropa und der GUS. Alle Länder-Analysen verstehen sich als Teil eines gemeinsamen Projektes, das der wissenschaftlich fundierten, allgemeinverständlich formulierten Analyse der Entwicklungen im östlichen Europa, der Offenheit für verschiedene inhaltliche Positionen und der kostenlosen und nicht-kommerziellen Information einer breit verstandenen interessierten Öffentlichkeit verpflichtet ist. Autor/innen sind internationale Fachwissenschaftler/innen und Expert/innen. Die Redaktionen der Länder-Analysen bestehen aus Wissenschaftler/innen mit langjähriger Forschungserfahrung.

Die deutschsprachigen Länder-Analysen werden gemeinsam von der Forschungsstelle Osteuropa an der Universität Bremen, dem Zentrum für Osteuropa- und internationale Studien, der Deutschen Gesellschaft für Osteuropakunde, dem Deutschen Polen-Institut, dem Leibniz-Institut für Agrarentwicklung in Transformationsökonomien und dem Leibniz-Institut für Ost- und Südosteuropaforschung herausgegeben. Die englischsprachigen Länder-Analysen erscheinen in Kooperation der Forschungsstelle Osteuropa mit dem Center for Security Studies (CSS) der ETH Zürich.

Die Länder-Analysen bieten regelmäßig Kurzanalysen zu aktuellen Themen, ergänzt um Grafiken und Tabellen sowie Dokumentationen. Zusätzlich gibt es eine Chronik aktueller Ereignisse.

\section{Belarus-Analysen}

Erscheinungsweise: zweimonatlich

Abonnement unter: http://www.laender-analysen.de/belarus/

\section{Caucasus Analytical Digest}

In englischer Sprache. Erscheinungsweise: zweimonatlich

Abonnement unter: http://www.css.ethz.ch/en/publications/cad.html

\section{Polen-Analysen}

Erscheinungsweise: zweimal monatlich

Abonnement unter: http://www.deutsches-polen-institut.de/newsletter/polen-analysen/

\section{Russland-Analysen}

Erscheinungsweise: zweimal monatlich

Abonnement unter: http://www.laender-analysen.de/russland/

\section{Russian Analytical Digest}

In englischer Sprache. Erscheinungsweise: zweimal monatlich

Abonnement unter: http://www.css.ethz.ch/en/publications/rad.html

\section{Ukraine-Analysen}

Erscheinungsweise: zweimal monatlich

Abonnement unter: http://www.laender-analysen.de/ukraine/

\section{Zentralasien-Analysen}

Erscheinungsweise: zweimonatlich

Abonnement unter: http://www.laender-analysen.de/zentralasien/ 